\title{
Closing integrative gaps in complex environmental governance systems
}

\author{
Harrison S. Fried $^{1}, \underline{\text { Matthew Hamilton }}^{1,2}$ and $\underline{\text { Ramiro Berardo }}^{1}$
}

\begin{abstract}
Modern environmental problems pose unique management challenges as they are usually interdependent in myriad, complex ways. Climate change is the ultimate example of a problem that forces environmental managers to confront highly interdependent challenges, such as invasive species, rising temperatures, and habitat loss. Interdependencies abound: for example, the issue of warming winter temperatures exacerbates the issue of invasive species, and a high prevalence of invasive species contributes to the issue of habitat loss. Ideally, stakeholders should account for these issue interdependencies by managing connected issues. Such activities close "integrative gaps," which refer to instances in which interdependent issues are managed independently. By closing integrative gaps, actors align management activities with underlying ecological processes. We focus on climate change adaptation governance in Ohio, USA, as a model study system and evaluate conditions that enable integrative gap closure through analysis of a network of adaptation actors and issues. Our findings show that actors are more likely to close integrative gaps between issue pairs that are highly biophysically interdependent, receive higher collective levels of public attention, and have garnered higher levels of progress. We also find that regional-scoped, specialized, and non-profit actors are most likely to manage for environmental interdependencies. We discuss how these findings advance theoretical understanding of institutional fitness and resilience in socialecological systems by revealing how actors navigate highly interdependent environmental governance settings.
\end{abstract}

Key Words: climate change adaptation; environmental governance; ERGM; institutional fitness; integrative gaps; policy issue interdependencies; social-ecological networks

\section{INTRODUCTION}

Individual environmental problems rarely exist in isolation. Ecological dynamics and feedbacks cause individual issues to become interwoven with other issues in complex ways (Lubell 2013, Hedlund et al. 2021). For instance, the spread of an invasive plant across a landscape can be accelerated by warming microclimate temperatures (Willis et al. 2010). The issue of invasive plants might also be facilitated by transportation-related seed dispersal (Taylor et al. 2012). These relationships mean that the issues of invasive species, transportation, and rising temperatures are interconnected. Such linkages exemplify one of the key challenges facing environmental decision makers - stakeholders with a vested interest in improving environmental outcomes are confronted with a constellation of issues and are tasked with managing the interconnections and evolving dynamics between them (McGinnis 2011, Lubell 2013, Bodin and Nohrstedt 2016, Gritsenko 2018, Mewhirter et al. 2018, Dennis and Brondizio 2020). The lack of well-defined definitions and rules, and the nested nature of modern environmental dilemmas qualify them as wicked problems that are uniquely difficult to manage (Rittel and Webber 1973).

Despite the many interdependencies between environmental issues (i.e., the change in one issue affects the outcome in another, or two issues have overlapping management activities; PhamTruffert et al. 2020, Hedlund et al. 2021), stakeholders do not always address these interdependencies in a holistic manner (Le Blanc 2015, Munsch et al. 2020). In complex governance systems, actors may operate more efficiently when they focus their limited capacity on a subset of interrelated issues because this, for example, can lower the environmental externalities that result from managing problems in a fragmented way. As environmental externalities can cause shocks and perturbations across an entire system, actors who manage for environmental interdependencies
- as opposed to those who manage an assortment of random, unrelated issues - improve system-level efficiency by internalizing the costs associated with integrative gap closure (Bergsten et al. 2019). From the standpoint of the entire system, appropriate management responses should ideally cover entire groups of interconnected environmental issues. A stakeholder with an ideal management approach would oversee an entire group of forest patches that are ecologically linked by seed dispersal, or collaborate with the managers of patches linked with their own, instead of managing linked patches independently (Bodin and Tengö 2012). Similarly, an ideal stakeholder would focus their efforts on a set of sustainability issues that are all influenced by each other, creating virtuous cycles of synergistic management (Folke et al. 2005, Pham-Truffert et al. 2020). Inappropriate or non-ideal management responses are those that address an issue without first attending to its potential feedbacks and interconnections.

The term "integrative gap" is used in the institutional fitness and environmental governance literatures (Young 2002, Folke et al. 2007, Epstein et al. 2015) to describe instances when a stakeholder fails to account for biophysical interdependencies in their management approach (Bergsten et al. 2019). Integrative gaps have implications for how well governing institutions reflect the biophysical system in which they are embedded, a key tenet of institutional and social-ecological fitness (Folke et al. 2007, Galaz et al. 2008, Lebel et al. 2013, Kininmonth et al. 2015). A great number of integrative gaps across a system may lead to fragmented management practices and ineffective environmental governance systems (Lubell 2013, Bodin 2017, Cejudo and Michel 2017). The closure of integrative gaps is desirable in that it is likely associated with improved sustainability outcomes (Bodin et al. 2014, Bergsten et al. 2019). Despite the increasingly recognized importance of policy issue integration for improving governance 
outcomes and efficiencies (Trein et al. 2019, Pham-Truffert et al. 2020), actors do not always close integrative gaps (Metz et al. 2020). We aim to understand the reasons why an actor is more or less likely to manage environmental interdependencies by answering the following research question: under what conditions do stakeholders close integrative gaps?

To answer this question, we investigate integrative gaps in the climate change adaptation governance system of Ohio (Midwest USA). Climate change is a prominent example of an issue that is associated with multiple, distinct sub-issues each related to specific adaptation challenges. Each issue poses unique challenges for local environmental managers. In Ohio specifically, managers must adapt to rising temperatures, heightened pest and pathogen pressures, and non-native species invasions, among other issues (Angel et al. 2018).

We operationalize climate change governance in Ohio as a multilevel network that is composed of over 600 stakeholders, 19 climate change adaptation issues, and their interconnections. This network can be categorized as a partially articulated socialecological network (Sayles et al. 2019), which can also be referred to as a "Type II" network where two of three possible link types are included (Kluger et al. 2020). Social-ecological networks capture complex interdependencies between social and ecological components (Sayles et al. 2019) and are increasingly turning into an important analytical focus for scholars interested in the study of environmental governance systems and their institutional fitness (Janssen et al. 2006, Treml et al. 2015, Ekstrom and Crona 2017, Bodin 2017, Angst 2019, Bodin et al. 2019, Barnes et al. 2019, Cinner and Barnes 2019, Metz et al. 2020, Hedlund et al. 2021). We test a series of hypotheses about the conditions under which an actor closes integrative gaps. Our results are important in that they extend existing literature on policy issue integration to uncover factors associated with actor-based integrative gap closure, which can improve social-ecological efficiencies and environmental outcomes (Bodin and Nohrstedt 2016, Bergsten et al. 2019, Brandenberger et al. 2021, Hedlund et al. 2021).

\section{THEORY}

\section{Environmental Interdependencies, Integrative Gaps, and Institutional Fitness}

Integrative gaps occur when actors fail to account for environmental interdependencies by working on a topic without paying attention to how it interacts with other topics (e.g., working on water quality without considering how increasingly common extreme weather events can impact said quality; Bergsten et al. 2019). In highly interdependent environmental systems, there are many pairs of connected issues, meaning that there are many possibilities for integrative gaps to occur. This complexity poses important challenges for environmental managers, particularly when environmental outcomes in the social-ecological systems in which they operate are not confined geographically and can trigger cascade effects that impact other systems (Kissinger et al. 2011, Centeno et al. 2015).

Examples of interdependent issue systems abound. In transcontinental aquatic systems, ecological interdependencies exist between the distinct issues of habitat restoration, water flow, and fisheries management (Munsch et al. 2020). In lake governance systems, interdependencies exist between the issues of water pollution and human health. There is also recognition that interdependencies occur across geographical boundaries, such as the linkages between rural and urban environmental issues (Buttel and Flinn 1977). In wildfire-prone regions, such as much of the Western USA, high ecological connectivity facilitates the spread of fire across jurisdictions and can link actors together based on shared wildfire risk (Hamilton et al. 2019). These examples speak to the fact that environmental interdependencies, which occur across spatial and temporal scales, should be a fundamental consideration in an actors' management strategy (Cash et al. 2006, Cumming et al. 2006).

At a global level of integrative gap closure, Reyers and Selig (2020) have proposed that future sustainable development goals (SDGs) create targets that emphasize social-ecological feedbacks and interdependencies that occur among the issues of biodiversity, ecosystem services, and sustainable development. They propose that future targets should fundamentally reject the "silo mentality" of separation between sustainability sectors and between scales of management (Griggs et al. 2014, Stafford-Smith et al. 2017, Reyers and Selig 2020). To promote the integrative gap closure of interconnected issues, SDG targets and similar policies themselves should reflect biophysical processes and feedbacks, emphasizing the tight interconnections that exist between issues (Le Blanc 2015, Elder et al. 2016). The holistic management of key relationships between SDGs has been identified as an entry point to replace "vicious cycles" of negative environmental feedbacks with synergistic "virtuous cycles" (Pham-Truffert et al. 2020).

In environmental governance contexts with many interdependent issues, the dynamics and feedbacks of an entire social-ecological system are greater than the sum of its parts. This means that complexity is derived from the relationships between issues and not merely because there are many issues (Levin 1999). In the same sense, the concept of ecosystem-based management has gained support over the past few decades and includes management approaches that consider entire systems and not separate components or sectors (Leslie and McLeod 2007, Levin et al. 2009). It is therefore counterproductive for managers to approach singular environmental issues without first attending to the roles they play in other domains. This is the challenge for environmental stakeholders: the high degree of complexity in navigating environmental interdependencies makes sustainable management an inherently difficult feat.

The coherence between actors' management approaches and patterns of ecosystem dynamics indicates how well an environmental governance system "fits" the ecological system in which it is embedded (Young 2002, Folke et al. 2007). Accordingly, a high prevalence of integrative gaps suggests poor institutional fitness (Lebel et al. 2013, Bergsten et al. 2019). Conceptually, the fitness of institutions is analogous to the fitness of organisms: the most "fit" organisms and institutions are those that are best adapted to their environmental setting. In governance systems, adverse environmental outcomes occur when actors fail to match their management approaches to the underlying realities of the social-ecological systems in which they operate (Epstein et al. 2015), similar to how a plant species that is poorly adapted to local weather conditions will eventually be outcompeted by another species, with implications for the overall ecosystem. 
Integrative gap closure improves institutional fitness because actors who manage interrelated issues are better able to holistically account for system feedbacks. Highly interconnected ecological systems can both facilitate the spread of disturbances and recovery across a landscape (Dakos et al. 2015), meaning that actors who close integrative gaps can oversee - and thus manage for-fundamental ecological processes. These biophysical interconnections are otherwise more difficult to observe and account for when approaching an issue in isolation (Armitage et al. 2009). Actors who extend their resources to manage multiple interconnected issues can improve their understanding of environmental interdependencies and use their newfound knowledge to guide their individual management decisions; an accumulation of enhanced management strategies across many actors can ultimately improve overall system governance.

Systems where actors largely fail to account for biophysical interdependencies in their management approaches (i.e., systems with a high prevalence of integrative gaps) could more easily be pushed past "tipping points" into undesirable, irreversible pathways toward degraded states (Galaz et al. 2008). Consequently, integrative gaps contribute to a decline in system resilience and an increase in vulnerability. We argue that integrative gaps are indicative of faulty management approaches because they represent a failure to account for the interdependencies of ecological processes. In a case study of agricultural systems in Australia, ecologically uninformed policies have led to a loss of social-ecological resilience and increased vulnerability (Anderies et al. 2006). Furthermore, one study found the largest contributor to institutional misfit in an estuary system was the lack of reflection of ecosystem relationships in policy documents (e.g., the co-occurrence of ecosystem components in the same sentence, paragraph, or unit of text of a policy document), emphasizing the need for ecologically informed management to improve system resilience (Ekstrom and Young 2009).

To establish the importance of being fit, we must first unpack how fitness shapes environmental outcomes, although there are few studies that do so (Bodin et al. 2019, Wang et al. 2021). There is no clear-cut, simple relationship between network structure and ecological outcomes or resilience (Janssen et al. 2006). However, the general assumption is that fit institutions lead to improved conservation success through enhanced management (Borowski et al. 2008, Guerrero et al. 2015, Ingold et al. 2018). This notion has been supported in an agricultural system case study (Bodin et al. 2014) and in Kenyan coral reef communities, where good social-ecological alignment was associated with improved reef ecosystem conditions (Barnes et al. 2019). Good fitness does not necessarily improve environmental outcomes, however: an empirical case of strong spatial fitness did not encourage effective drinking water regulations in the Rhine River catchment (Ingold et al. 2018). In the transcontinental aquatic system example, the simultaneous management of fisheries, water flow, and habitat restoration was found to benefit diadromous fish species like Pacific salmon (Oncorhynchus spp.) that migrate between rivers and oceans (Munsch et al. 2020). The closure of an integrative gap in this system, for instance, might occur when an actor utilizes water discharge and habitat quality data to decide the environmentally optimal location to open a new fishery.

\section{Understanding When Integrative Gaps Are Closed}

Given the importance of well-aligned social-ecological systems for sustainable governance arrangements (Bodin 2017), we devise a series of hypotheses that investigate the conditions and attributes that could enable an actor to close integrative gaps. We argue that the conditions associated with integrative gap closure can be leveraged to improve social-ecological fitness and thereby foster system sustainability. We study integrative gap closure at the level of the actor, not the system, although the closure of integrative gaps is efficient both for individual actors who have limited resources and for entire governance systems when individual actors internalize the externalities stemming from between-issue dynamics (Kininmonth et al. 2015). An integrative gap (Fig. 1A) is closed when an actor manages both of a pair of related issues (Fig. 1B), requiring both potential social-ecological edges to be fulfilled. We test for the conditions and attributes that lead actors to form social-ecological edges that close integrative gaps.

Fig. 1. A visualization of integrative misfit (A) and integrative fit (B) depending on the absence (dashed lines) or presence (solid lines) of a tie between an actor (red circle) and two biophysically related issues (green circles), regardless of the direction of the relationship between the two issues.
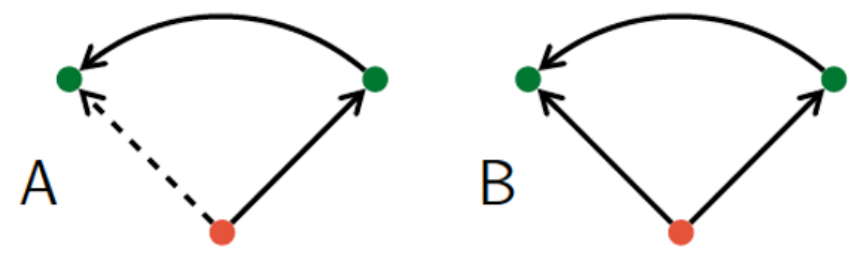

Not all pairs of issues are made equally: instead, they vary in strength and importance based on several factors. What this means for stakeholders is that some pairs of interrelated issues are more essential to manage than others, or that they require more immediate attention. Actors should ideally choose to work on issues that are the most closely related to the other issues they work on, creating efficient "virtuous cycles" that prioritize synergies (Elder et al. 2016, Pham-Truffert et al. 2020). For example, an actor who manages water quality should also manage the issue of soil erosion, as the latter can increase turbidity - often directly associated with water pollution (Lal and Stewart 1994). In this example, an actor can synergistically manage both soil erosion and water quality with a single action, such as a stream bank stabilization project. On the other hand, an actor who manages water quality and air quality simultaneously would be closing a less important integrative gap because, although water quality and air quality indeed are interrelated (e.g., via carbon dioxide emissions that indirectly stimulate algal biomass growth; Chen et al. 2019), this interrelation is more subtle compared with others. As actors possess limited resources and therefore cannot necessarily manage a great number of issues (Zhu 1992, McCann 2013), efficient social-ecological alignment requires actors to prioritize integrative gap closure for closely interconnected issues, and so we should expect to see fewer efforts to jointly work on loosely related issues. Accordingly, our first hypothesis is related to the closure of integrative gaps based on the strength of ecological interdependencies. 
$\mathrm{H}_{1}$ : Actors are more likely to close integrative gaps for pairs of topics that are more strongly interdependent.

\section{Issue attributes}

Beyond the strength of interconnections between issues, an actor's propensity to close integrative gaps may be impacted by certain relevant attributes of the issues themselves. One prominent attribute of issues that we believe to explain integrative gap closure tendencies is public attention. Certainly, some issues receive more public attention than others, such as media attention (Angst 2019). Select issues may demand the public's attention, including the attention of key actors (Kingdon 1984, Berardo et al. 2015). Stakeholders may be more likely to recognize high-attention issues as more important to manage (Wlezien 2005), which could be a precursor for integrative gaps to be closed for high-attention issues. We expect the connections between popular issues are themselves more publicly known and therefore more popular, such as the interdependency between water quality and human health that receives high levels of attention during toxic algal bloom events. We similarly expect that because popular issues are connected to each other via popular interdependencies, they are management priorities for environmental stakeholders. Accordingly, we propose $\mathrm{H}_{2}$ :

$\mathrm{H}_{2}$ : Actors are more likely to close integrative gaps between issues for which there are higher levels of public attention.

Additionally, we posit that integrative gap closure is associated with higher levels of progress made on resolving issues. We define progress as the amount of headway made on resolving or adapting to an issue, which we gauge based on a series of interviews with experts who indicated their perception of issue progress. We use perceived issue progress as a proxy measurement for environmental outcomes and expect that integrative gap closure leads to high levels of progress (Lubell et al. 2017a). This is because social-ecological alignment is generally assumed to lead to conservation success (Bodin et al. 2014). Social-ecological alignment might mean that environmental managers are wellpositioned to manage ecological connectivity in ways that prevent non-native species invasions (Lubell et al. 2017a) or enable essential species dispersal between habitat patches (Bodin and Tengö 2012, Bergsten et al. 2014). In testing for an association between integrative gap closure and issue progress, we must also recognize the possibility that high levels of progress could make integrative gap closure more likely. For instance, issue pairs with high progress levels likely have higher levels of scientific certainty, which in turn should reduce the transaction costs that actors bear when managing for uncertain and complex ecological interdependencies (Lubell et al. 2017b). Our expectation is that integrative gap closure leads to higher levels of issue progress and improved environmental outcomes, and therefore propose $\mathrm{H}_{3}$.

$\mathrm{H}_{3}$ : There is a higher level of progress solving issues for which fewer integrative gaps exist.

\section{Actor Attributes}

We expect that the ability of actors to work on multiple issues (and therefore be able to close integrative gaps) varies with an actor's organizational type and organizational scope. To manage a single issue (i.e., work on projects, programs, and advocacy), an actor must expend resources such as time, money, and human capital (Zhu 1992). Then, to manage multiple issues, or a great number of issues, actors must spend an even greater sum of resources. We predict that because different types of organizations (e.g., NGOs, governmental agencies, universities, etc.) are differentially equipped with resources, organizational type plays a key role in actor-issue engagement, and therefore in integrative gap closure. Government actors are heavily solicited as collaborative partners in management efforts because they often occupy the role of a broker-government actors use their financial, human, and political resources to connect otherwise unconnected actors, leading to the exchange of non-redundant resources (Berardo 2009, Henry 2011). Furthermore, government actors tend to have more experience, authority, and resources, and participate in decision-making forums more often than other types of actors (Leifeld and Schneider 2012, Lubell et al. 2014, Lubell at al. 2017b). Beyond these factors, government actors are often mandated or are implicitly expected to perform functions that protect the public good (i.e., social contract theory; Locke 1965, Rosseau 1973, O'Brien et al. 2009), which can potentially be completed through integrative gap closure. We expect that these advantages and responsibilities of government actors position them to better manage for environmental interdependencies than non-government actors.

$\mathrm{H}_{4}$ : Government actors are more likely to close integrative gaps compared with non-government actors.

Furthermore, the ability for an actor to overcome the transaction costs associated with working on multiple issues may be a challenge for small-scale stakeholders because they would need to spend major resources to gain technical, social, and political capital for the management of each issue (Angst 2019). As such, an actor's geographic scope (e.g., local, regional, state) may dictate whether it should specialize on a single issue or a subset of interrelated issues. In addition to impacting the issues an actor engages in, geographic scope impacts the forums that an actor participates in. Actors are less likely to participate in forums that do not match their own organizational level (Hamilton et al. 2018). Geographic scope is an important consideration in matching management to ecosystem dynamics at different spatial scales: social-ecological mismatches can occur in cases when social actors responsible for managing some part of the environment operate at a geographic scale inconsistent with the scale of environmental processes (Cumming et al. 2006). Because there often are spatial incongruencies between patterns of ecosystem services and the policies meant to sustain them (Bergsten et al. 2014, Qiu et al. 2017), the scope of organizations involved in the governance of biophysical issues plays an essential role in social-ecological alignment. We posit that actors who operate at wider geographic scales are better able to account for jurisdiction-crossing issue interdependencies and resultingly are more likely to manage for them. Therefore, we propose one final hypothesis related to geographic scope:

$\mathrm{H}_{5}$ : The greater an actor's geographic scope, the greater the likelihood that it will close integrative gaps.

\section{METHODS}

To test our hypotheses, we collected data on a social-ecological system where several stakeholders manage a subset of climate change issues, closing some, but not all, integrative gaps. Our social-ecological network included 19 climate change-related adaptation issues relevant to Ohio, the actors who work on these 
Fig. 2. A drawing of a social-ecological system consisting of interdependent climate change issues and four actors. The green arrows represent issue interdependencies that occur across the landscape, which are directed and weighted. The blue lines indicate the issues that the actor manages. Integrative gaps occur when actors manage only one issue of a related pair of issues.

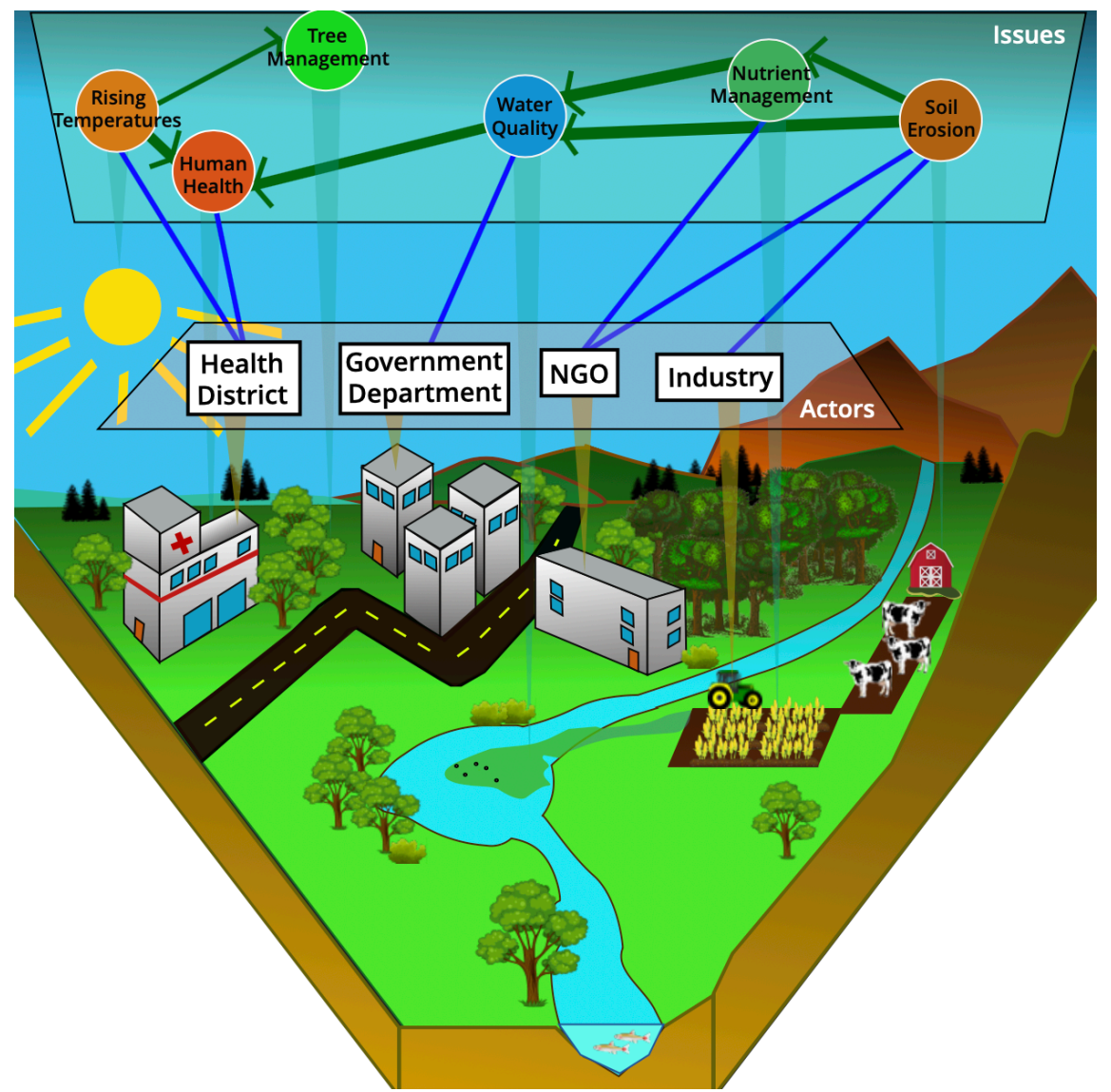

issues, and the relationships that occur between them. Socialecological network studies emphasize the relationships between two sets of system components (social and ecological) rather than just social-social ties or ecological-ecological ties (Bodin et al. 2019, Sayles et al. 2019). In the social-ecological network, we focus on the ties between issues and the ties between actors and issues (typically referred to as affiliation ties). We use issue interdependencies as edge covariates to explain social-ecological edge formation.

\section{Issue Interdependency Network}

The issues in our two-mode network are themselves intertwined and we aim to explore these interrelationships. We first identified the issues as described in the U.S. Global Climate Research Program's (USGCRP) Fourth National Climate Assessment (FNCA), which is a comprehensive report that provides the state of the science on climate change in the USA. Because climate change affects regions in unique ways, some effects are heightened in various locations (Roesch-McNally et al. 2020). To make regional climate change effects more salient for local stakeholders, the USGCRP provides regional summary reports of the FNCA and includes key messages that describe the most pressing issues for each region (Angel et al. 2018). A diverse array of participants and voices contributed to each regional FNCA chapter, meaning that each chapter identifies problems from a multidisciplinary perspective (Roesch-McNally et al. 2020). The Midwest chapter, which we use in this analysis, outlines six key messages that are important from an adaptation standpoint in the region. These key messages focus on agriculture, forestry, biodiversity and ecosystems, human health, transportation and infrastructure, and community vulnerability. In May of 2019, each of this paper's authors read through the key messages to identify specific collective action problems, then met to reconcile differences in individual lists, resulting in a total of 19 specific adaptation issues relevant in Ohio, shown in Table 1. These adaptation issues are the ecological nodes in the network.

A classic use of ecological networks has been to set habitat patches, specific locations, or ecosystem types as ecological nodes (Sayles et al. 2019). Pittman and Armitage (2017), for instance, use types of habitat as ecological nodes, including seagrass and reef habitat, to investigate social-ecological fitness across a landsea interface. Alternative types of ecological nodes have been used by some authors, including sustainability issues like "human- 
Table 1. Climate change adaptation issues and the adaptation activities that correspond to them. The issue list and their associated activities were derived through a text analysis of the Midwest Report of the Fourth National Climate Assessment (Angel et al. 2018).

\begin{tabular}{ll}
\hline \hline Issue & Activities \\
\hline Air Quality & Air quality monitoring, permitting, and enforcement \\
Forests & Forest protection, forest biodiversity management \\
Green Infrastructure & Rain barrels, green roofs, backyard homesteading \\
Green Spaces & Park management and trail-way development \\
Habitat Loss & Habitat preservation, habitat creation, buffer zones \\
Human Health & Climate-related health advocacy and care \\
Invasive Species & Invasive species removals, invasive species education \\
Land Use & Conservation easements, sub-urban sprawl, research \\
Natural System Restoration & Dam removal, habitat restoration or enhancement \\
Nutrients & Nutrient diversion, fertilizer management practices \\
Pests and Pathogens & Crop pest and pathogen research, management plans \\
Rising Temperatures & Temperature adaptation, air conditioning \\
Soil Erosion & Cover crops, conservation tillage, filter strips \\
Storm Water & Installation of runoff diversion infrastructure \\
Transportation & Sustainable transportation systems and clean fuels \\
Tree Management & Tree planting, urban tree canopy assessments \\
Vulnerable Communities & Promoting food access and resilience to hazards \\
Warm Season & Weather pattern adaptation and management \\
Water Quality & Water pollution abatement and clean-up \\
\hline
\end{tabular}

wildlife conflict," "food access," and "agricultural expansion" (Bergsten et al. 2019). Specific ecosystem services have been used as ecological nodes as well (Alonso Roldán et al. 2015).

We then measured connections among the 19 issues based on their approximated biophysical relationships according to the opinions of 57 experts who we interviewed for this project. From May to August 2020, we conducted a series of semi-structured interviews with local experts to understand how each issue affects and is affected by every other issue, generating a score and description for every possible issue-issue pair. Interviewees were told to identify relationships between issues that existed at the time of the interview. We identified experts for each of the 19 issues through online searches and interviewed three experts for each issue. For example, a water quality expert answered questions about how water quality affects all other issues, and how all other issues affect water quality. Each interview produced a cognitive map of issue-issue relationships, and we combined all 57 cognitive maps to construct the issue interdependency network. The issue network thus captures the interdependencies between issues as assessed by the experts, thereby synthesizing multiple (academic and non-academic) forms of knowledge (Dray et al. 2007, Jones et al. 2011, Pittman and Armitage 2017). We interviewed relevant faculty members from local universities in addition to field technicians who work in Ohio. Of the 57 experts who were interviewed, 18 were faculty members from universities, 20 were scientists from government departments, and 19 were scientists from NGOs and other organizations.

Table 2 shows three issue pairs and their bidirectional connections, scores, and descriptions; the pairs included in the table were specifically chosen to demonstrate variability in issue interdependencies. Scores range from 0 (no interdependency) to 1 (strongest interdependency). The strength for each directed edge $\left(\mathrm{X}_{i j}\right)$ is the average of six expert responses, three experts from each topic ( $i$ and $j$ ). Then, we took the average of the directed edge weights $\left(\mathrm{X}_{i j}\right.$ and $\left.\mathrm{X}_{j i}\right)$ to produce undirected edge weight scores for each issue-issue dyad. For example, the undirected edge weight for the interdependency between "Air Quality" and "Forests" is 0.575 , the mean of 0.50 (impact of "Air Quality" on "Forests") and 0.65 (impact of "Forests" on "Air Quality" see Table 2).

To assess the level of public attention that each issue commanded (information needed to test $\mathrm{H}_{2}$ ), we used "Google Trends," which provides the relative popularity of unique search terms during a controllable time range and location. We obtained the relative search popularity in Ohio for each of the 19 climate adaptation issues for each week from October of 2016 to November of 2019, then averaged these scores to produce a single public attention score for each issue. To obtain perceived progress scores, we asked the same experts to indicate their agreement (along a five-point Likert scale) with the following statement: "Over the past 50 years, there has been a significant amount of progress made toward addressing this issue." Response scores were averaged for each issue, producing a perceived progress score for every issue, which we use to test $\mathrm{H}_{3}$.

\section{Actor-Issue Linkages}

The social nodes in our analysis are organizations involved in management efforts in Ohio of at least one of the 19 issues we identified. From June through August of 2019, we identified organizations using an internet-based snowball approach (Hileman and Lubell 2018). We started by identifying a group of seed actors who work on climate adaptation in Ohio, which included several large environmental organizations near our home institution, the Ohio State University. Then, we conducted a hyperlink analysis from seed actor websites to identify the organizations with whom they work on climate change adaptation activities; these additional actors were often listed as partners. The snowball process was repeated until no new actors were revealed, resulting in a network of 659 actors. We coded several organizational attributes for each actor, including organization type (e.g., NGO, state government) and organization scope (e.g., local, sub-state regional, state, national). 
Table 2. Sample bidirectional linkages, strengths, and descriptions for three pairs of issues. For each issue-issue pair, tie strength is calculated as the average strength of both directions (A to B and B to A). For instance, the edge strength between Air Quality and Forests is 0.575 . The data displayed are the aggregate score and description of issue interdependencies based on expert interviews, where the edge strength between Air Quality and Forests is the average response of three Air Quality experts and three Forest experts.

\begin{tabular}{|c|c|c|c|c|}
\hline Issue A & Impact On & Issue B & Strength & Description of Impact \\
\hline Nutrients & $->$ & Soil Erosion & 0.67 & $\begin{array}{l}\text { Soil nutrients promote plant growth and root cover, which } \\
\text { stabilize soil erosion }\end{array}$ \\
\hline Soil Erosion & $->$ & Nutrients & 0.83 & $\begin{array}{l}\text { Eroded soil particles carry attached nutrients along with them, } \\
\text { resulting in nutrient influxes in water bodies }\end{array}$ \\
\hline Air Quality & $->$ & Forests & 0.50 & $\begin{array}{l}\text { Forests may be impacted by particulate matter and sulfates, } \\
\text { although healthy forests are generally resilient to these impacts }\end{array}$ \\
\hline Forests & $->$ & Air Quality & 0.65 & $\begin{array}{l}\text { Forests filter out some air contaminants and they capture } \\
\text { carbon dioxide, leading to improved air quality }\end{array}$ \\
\hline Water Quality & $->$ & Human Health & 1.00 & $\begin{array}{l}\text { Drinking water is essential to life; water pollutants can be } \\
\text { deadly and lead to chronic health problems if ingested }\end{array}$ \\
\hline Human Health & $->$ & Water Quality & 0.27 & $\begin{array}{l}\text { People in poor health have a limited ability to lessen their } \\
\text { personal impact on water quality; poor environmental health } \\
\text { can spur water quality improvement initiatives }\end{array}$ \\
\hline
\end{tabular}

We measured actor-issue linkages based on the information displayed on organizations' websites; most common were strategic plans, project descriptions, or annual reports. Specific activities listed on individual actor websites were used to substantiate actor-issue linkages. For instance, a mention that the organization is active in promoting the use of rain barrels would create a tie linking the actor to the issue "green infrastructure." Table 1 displays a list of adaptation activities that are associated with each adaptation issue.

\section{Bipartite Exponential Random Graph Models}

To test our hypotheses, we use bipartite exponential random graph models (ERGMs), which are statistical models used to determine whether theoretically important network configurations appear more or less frequently in an empirical network relative to what would be expected by chance-i.e., using distributions of configuration counts from a large number of randomly generated networks with similar characteristics as the empirical network (Robins et al. 2007, Lusher et al. 2013). Specifically, provided a set of parameters that represent theoretically important configurations as well as control parameters, ERGMs iteratively refine parameter estimates using Markov chain Monte Carlo simulation to approximate the characteristics of the empirical network (i.e., the network observed through the data collection process). For each parameter included in an ERGM, the model generates an estimate and a standard error. Estimates that are significantly greater (less) than zero indicate that characteristics associated with the parameters are over- (under-) represented in the empirical network. It is common to start with simple models, then refine them in additional models by continually adding new parameters that represent additional processes believed to contribute to the structure of the empirical network (Robins et al. 2011, Bodin et al. 2016).

To estimate our models, we employ the package "ERGM" (Hunter et al. 2008) in R (R Core Team 2020) and construct four models that successively build from each other. We test the propensity for actors to close integrative gaps for pairs of issues that are strongly biophysically interconnected $\left(\mathrm{H}_{1}\right)$ using issue interconnection scores as an edge covariate. We include additional edge covariate terms that test for integrative gap closure tendencies based on public attention to the issues and perceived progress made on them $\left(\mathrm{H}_{2}\right.$ and $\left.\mathrm{H}_{3}\right)$. To test $\mathrm{H}_{4}$ and $\mathrm{H}_{5}$, we use two different effects, including: (1) baseline issue engagement (nodefactor) and (2) integrative gap closure likelihood (edgecov) for each actor type and scope level, where Federal Government and National are used as reference categories, respectively. Figure 3 displays the network configurations for each of the hypotheses. We differentiate issue engagement from integrative gap closure, where issue engagement is interpreted as the propensity for a given actor to work on a given issue, whereas integrative gap closure is the likelihood that an actor closes an integrative gap.

Finally, we include several endogenous parameters that test network tendencies for social-ecological edge formation (edges) and actor-level degree distribution (the number of issues a given actor works on; $g w b 1 d e g$ ), which are explained in greater detail in Appendix 1. We also include baseline tendencies for actors engaging in issues based on attention and progress as exogenous control parameters.

The first model shows baseline results, and additional models add parameters that test hypotheses related to integrative gap closure. We include actor type and scope parameters in their own models because collinearity problems cause the model to not converge when they are included together. There were consistent parameter estimates and standard errors for the terms that were used in multiple models, indicating the robustness of our findings. Appendix 2 includes a table that displays the $\mathrm{R}$ code and data source for each of the "ERGM-terms" in the models. Goodness of fit diagnostics revealed that the models were well-fit to the data (Appendix 3).

\section{RESULTS}

Table 3 presents the parameter estimates and standard errors for the four bipartite ERGMs. The first hypothesis, which expects that actors close integrative gaps for pairs of issues that are closely interdependent, was supported by the positive and significant parameter estimate for the integrative gap closure term. Likewise, there were positive and significant parameter estimates for the public attention integrative gap closure terms, signifying that actors are more likely to close integrative gaps for pairs of issues 
Fig. 3. Network configurations and descriptions used in the bipartite exponential random graph models.

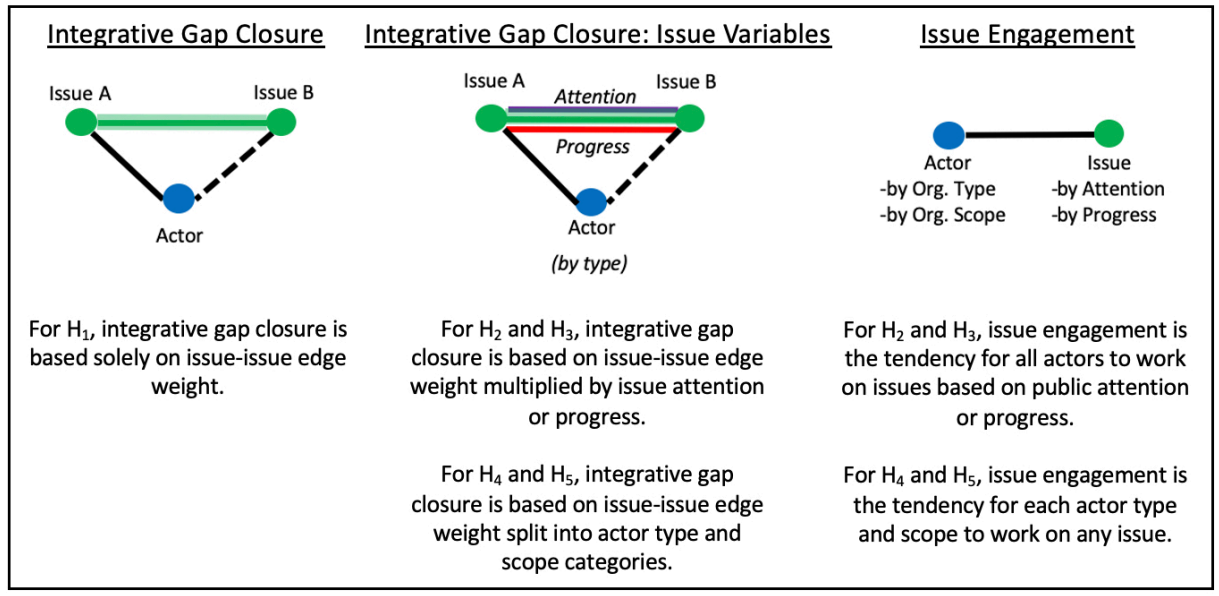

that receive high levels of public attention. This finding provides support for $\mathrm{H}_{2}$. We also find support for $\mathrm{H}_{3}$ because the issue progress effect indicates that actors tend to close integrative gaps for pairs of issues with high progress. The parameter estimates for the public attention and issue progress terms are based on edge covariate matrices that also account for issue interdependency strengths from $\mathrm{H}_{1}$, so they should be interpreted as the added effect (i.e., the bonus likelihood of integrative gap closure) for public attention and issue progress, respectively. Additionally, the results indicate that actors were more likely to engage in issues that receive more public attention and less likely to engage in issues that have high levels of progress, indicated by the positive and negative parameter estimates for the issue attention - engagement and issue progress - engagement control terms (Table 3 ).

We did not find support for $\mathrm{H}_{4}$, as government actors were no more likely to close integrative gaps than other types of actors. We expected State Government actors to be among the most likely actor types to close integrative gaps, and our results show the opposite. However, Special District actors - which are indeed a type of government actor, and mostly include Soil and Water Conservation Districts and Storm Water Management Districts -were the most likely to close integrative gaps. The Special District actors closed integrative gaps at high rates despite engaging in fewer issues, suggesting that they specialize on subsets of highly interdependent issues. Thus, the distinction between government and non-government organizations does not explain integrative gap closure; instead, the results show that specialized actors (except for industry actors) tend to close integrative gaps.

Furthermore, we found that the likelihood of integrative gap closure increased with actor geographic scope but only up to the regional level; state-level actors were not more likely to close gaps than federal-level actors (the reference category). Therefore, we reject $\mathrm{H}_{5}$ because integrative gap closure does not increase linearly with scope. We discuss the practical and theoretical implications of our results in the following section.

\section{DISCUSSION}

We modeled a climate change adaptation network to test expectations about the factors that lead actors to manage for environmental interdependencies, which is a critical task in achieving effective environmental governance. To understand why some interdependencies are targeted for management more than others, we must first recognize that it is unrealistic for actors to manage all interdependencies in dynamic, evolving, and complex systems (Galaz et al. 2008, Imperial et al. 2016), especially because they have limited resources, environmental knowledge, and organizational capacity (McCann 2013).

The results from our models indicate that actors are more likely to manage for environmental interdependencies that are strongly connected, receive more public attention, and have had more progress made on them. We also found that integrative gap closure likelihood varies with actor type and geographical scope of operation. The attributes that we tested begin to explain why some environmental interdependencies are managed more than others, with crucial implications linking environmental governance structure and outcomes. Throughout the rest of this section, we discuss plausible explanations and implications for each of the conditions that impact integrative gap closure.

\section{Closing Integrative Gaps}

In this study, we are interested in examining how issue interdependencies are managed by single actors or organizations. We do not consider formal collaborative processes as a form of integrative gap closure, although we acknowledge that there is an extensive body of work that does (see, for instance, Guerrero et al. 2015, Bodin and Nohrstedt 2016, Bodin 2017, Tosun and Lang 2017, Widmer et al. 2019, Hedlund et al. 2021). Our approach rests on the assumption that an important step of successful environmental management is for individual actors to understand the complex interconnections that exist among the myriad issues that deserve attention. Without this awareness, institutional fitness is likely to be lower, which would lead to the exacerbation of environmental problems (Bodin et al. 2014, Bergsten et al. 2019, Angst 2019).

Our findings show that actors tend to close integrative gaps for pairs of issues that are more closely interdependent. This suggests that climate adaptation actors in Ohio recognize important biophysical processes and manage for them, improving system- 
Table 3. ERGM results from the four models. The "Integrative Gap Closure - Edge Weight" parameter is not included in the Actor Type and Actor Scope models because it is collinear with the integrative gap closure parameters for actor type and actor scope. "Federal Government" and "National" are used as reference categories for actor type and actor scope, respectively. The control parameter "gwb1deg" measures the distribution of the number of issues that actors address, and specifically the tendency for actors to each work on approximately the same number of issues (see Appendix 1 for more details). ${ }^{* * *} \mathrm{p}<0.001,{ }^{* *} \mathrm{p}<0.01,{ }^{*} \mathrm{p}<0.05$.

\begin{tabular}{|c|c|c|c|c|c|}
\hline Category & Term & $\begin{array}{l}\text { Null Model } \\
\text { Estimate (SE) }\end{array}$ & $\begin{array}{l}\text { Main Effects } \\
\text { Estimate (SE) }\end{array}$ & $\begin{array}{l}\text { Actor Type } \\
\text { Estimate (SE) }\end{array}$ & $\begin{array}{l}\text { Actor Scope } \\
\text { Estimate (SE) }\end{array}$ \\
\hline \multirow[t]{3}{*}{ Issue Covariate } & Integrative Gap Closure & $0.72(0.10)^{* * *}$ & & & \\
\hline & Issue Concern - Int. Gap Closure & & $0.08(0.03)^{* *}$ & $0.07(0.03)^{*}$ & $0.07(0.03)^{*}$ \\
\hline & Issue Progress - Int. Gap Closure & & $0.06(0.01)^{* * *}$ & $0.06(0.01)^{* * *}$ & $0.06(0.01)^{* * *}$ \\
\hline \multirow[t]{14}{*}{ Actor Type } & State Government - Int. Gap Closure & & & $-0.06(0.44)$ & \\
\hline & State Government - Issue Engagement & & & $-0.10(0.30)$ & \\
\hline & Local Government - Int. Gap Closure & & & $0.85(0.41)^{*}$ & \\
\hline & Local Government - Issue Engagement & & & $-0.77(0.29)^{* *}$ & \\
\hline & Special District - Int. Gap Closure & & & $1.97(0.27)^{* * *}$ & \\
\hline & Special District - Issue Engagement & & & $-1.52(0.21)^{* * *}$ & \\
\hline & Environmental NGO - Int. Gap Closure & & & $0.62(0.18)^{* * *}$ & \\
\hline & Environmental NGO - Issue Engagement & & & $-0.75(0.16)^{* * *}$ & \\
\hline & Industry Organization - Int. Gap Closure & & & $0.23(0.32)^{* * *}$ & \\
\hline & Industry Organization - Issue Engagement & & & $-0.78(0.22)^{* * *}$ & \\
\hline & Education/University - Int. Gap Closure & & & $0.20(0.30)$ & \\
\hline & Education/University - Issue Engagement & & & $-0.32(0.21)$ & \\
\hline & Coalition Group - Int. Gap Closure & & & $1.05(0.40)^{* *}$ & \\
\hline & Coalition Group - Issue Engagement & & & $-0.79(0.28)^{* *}$ & \\
\hline \multirow[t]{8}{*}{ Actor Scope } & Local - Int. Gap Closure & & & & $0.63(0.27)^{*}$ \\
\hline & Local - Issue Engagement & & & & $-0.66(0.19)^{* * *}$ \\
\hline & County - Int. Gap Closure & & & & $1.42(0.21)^{* * *}$ \\
\hline & County - Issue Engagement & & & & $-1.14(0.15)^{* * *}$ \\
\hline & Regional - Int. Gap Closure & & & & $1.66(0.29)^{* * *}$ \\
\hline & Regional - Issue Engagement & & & & $-1.27(0.21)^{* * *}$ \\
\hline & State - Int. Gap Closure & & & & $-0.04(0.21)$ \\
\hline & State - Issue Engagement & & & & $-0.26(0.14)$ \\
\hline \multirow[t]{4}{*}{ Control Parameters } & Edges & $-0.75(0.11)^{* * *}$ & $-1.43(0.15)^{* * *}$ & $-0.80(0.17)^{* * *}$ & $-0.85(0.14)^{* * *}$ \\
\hline & gwbldeg.fixed.2 & $-1.87(0.14)^{* * *}$ & $-1.04(0.17)^{* * *}$ & $-0.83(0.19) * * *$ & $-0.91(0.18)^{* * *}$ \\
\hline & Issue Concern - Issue Engagement & & $0.01(0.00)^{* * *}$ & $0.01(0.00)^{* * *}$ & $0.01(0.00)^{* * *}$ \\
\hline & Issue Progress - Issue Engagement & & $-0.16(0.04) * * *$ & $-0.17(0.03)^{* * *}$ & $-0.17(0.03)^{* * *}$ \\
\hline \multirow[t]{3}{*}{ Fit } & $\mathrm{AIC}$ & 11982.42 & 11497.85 & 11451.82 & 11449.6 \\
\hline & $\mathrm{BIC}$ & 12004.73 & 11549.90 & 11600.53 & 11553.69 \\
\hline & Log Likelihood & -5988.21 & -5741.93 & -5705.91 & -5710.80 \\
\hline
\end{tabular}

wide institutional fitness and adaptive capacity through the creation of "virtuous cycles" (Pham-Truffert et al. 2020). Our findings suggest that actors can craft their portfolio of issues to manage for crucial interdependencies, a desirable feature in social-ecological systems that are highly dynamic (Elder et al. 2016, Metz et al. 2020). The ability of actors to focus on the most important interdependencies speaks to efficient social-ecological alignment because of the resource limitations and transaction costs actors face when working on many issues (Zhu 1992, McCann 2013). From a practitioner's standpoint, we believe these results should be seen with optimism, as they suggest that there is a good amount of integration between climate adaptation initiatives in Ohio and the issues emphasized in the FNCA report. Because we collected issue interconnection data based on expert responses, it is also encouraging that actors tended to close integrative gaps for the pairs of issues that experts indicated were closely interdependent. In other words, actor-issue linkages across the network tended to reflect the expert-elicited cognitive map of issue interconnections.

According to our results, actors tend to close integrative gaps for pairs of issues that collectively receive high levels of public attention. We suspect that the interdependency between two high- attention issues would receive high attention itself. For example, two issues that garner high levels of public attention are transportation and air quality, which are interdependent because transportation-related emissions release many pollutants into the air. Because the public is comparatively highly attentive to both issues in this relationship, it would follow that the interdependencies between them are also well known or are at least well known to environmental managers and therefore demand their attention and subsequent action (Berardo et al. 2015). Our findings on integrative gap closure based on public attention match those of Brandenberger et al. (2021), who found that policy issue popularity was a key factor in an actor's involvement in multiple issues in the same issue subsystem.

We also explored the association between integrative gap closure and perceived issue progress to better understand the connection between social-ecological alignment and environmental outcomes. Because our data are cross-sectional, we are unable to establish causality, and consequently there are two plausible interpretations for the relationship between perceived issue progress and integrative gap closure. One interpretation is that high levels of progress improve the likelihood of integrative gap closure. There are likely more potential partners and better 
resource-sharing opportunities (e.g., policy forums) for pairs of issues with high collective progress, lowering the transaction costs associated with integrative gap closure (Lubell et al. 2017b). The second interpretation is that the closure of integrative gaps leads to improvements in governance outcomes, which translates into high levels of reported progress made on these issues. This version is far more interesting because it has major implications for environmental governance and sustainability outcomes. To make this interpretation, we are required to use perceived issue progress as a proxy measurement of environmental outcomes, equating high issue progress with positive environmental gains. In this interpretation, our model results provide evidence of the benefits of good social-ecological alignment on conservation outcomes, substantiating a growing literature of work to correlate socialecological fit to improved environmental outcomes (Bergsten et al. 2014, Bodin et al. 2014, Lubell et al. 2017a). Future work can utilize longitudinal data to better understand the ways in which closed integrative gaps lead to changes in environmental conditions.

Integrative gap closure likelihood varied with organization type and scope, although not in the ways we expected. From our results, we learn that certain types of actors are more likely than others to close integrative gaps and thereby contribute more to institutional fitness, based on the difference between the number of issues an actor works on (issue engagement) and the number of integrative gaps the actor closes. Put differently, certain actor types more efficiently devote their resources toward the management of environmental interdependencies and contribute more to institutional fitness, perhaps based on their freedom in choosing issues to manage. Ultimately, our model results point to an important conclusion on the effects of actor type on integrative gap closure: specialized and non-industry actors outperformed non-specialized actors.

Specialized and non-industry actors are organizations that focus on few issues and are not primarily profit-driven enterprises. This categorization includes Special Districts, NGOs, Coalition Groups, and Local Government actors. As these actors are either interest groups (NGOs and Coalition Groups) or small-scale government bodies (Special Districts and Local Government), they are each motivated to protect the public good and therefore should be inclined to close integrative gaps (O'Brien et al. 2009). In particular, because Special Districts and Local Government actors tend to have high levels of experience, authority, and resources, it is possible these advantages facilitated their contribution to social-ecological alignment (Leifeld and Schneider 2012, Lubell et al. 2017b). Additionally, knowledge advantages could play a role in actor-type differences in integrative gap closure. Specialized and non-industry actors could have greater technical information about fundamental ecological pathways than other actors. Also, different types of actors could have differential freedoms in choosing issues to work on - actors with less freedom to choose issues may be less likely to close integrative gaps. We expect that freedom in choosing issues varies with actor typefor example, certain laws or statutes might restrict government agencies to managing just one main issue. Future studies could test other actor attributes, such as resource capacity (Emerson et al. 2012), perceptions of responsibility in protecting the public good (O'Brien et al. 2009), relative experience (Lubell et al. 2017b), or leadership skills (Olsson et al. 2007, Emerson et al.
2012). However, we emphasize that specialized and non-industry actors tend to improve institutional fitness by closing integrative gaps.

The geographic scope at which organizations operate also plays a major role in integrative gap closure. Notably, regional actors closed integrative gaps at the highest rate compared with the baseline comparison category of national-level organizations, despite working on the fewest number of issues. This means that the regional level could operate as a "goldilocks" position in which management actions could be particularly effective. Unlike local actors, regional stakeholders are better positioned to observe and act on ecological processes whose scales exceed the merely local levels of municipal jurisdictions, which might give them the chance to reduce scale mismatches (Cumming et al. 2006). In such cases, regional stakeholders may be better equipped to reduce the high transaction costs associated with obtaining key scientific information, searching for collaborative partners, or resolving jurisdictional disputes - all of which may be difficult for city government departments or local NGOs (McCann 2013). In regional climate change adaptation governance, where conditions vary with location, our findings suggest the importance of regional actors in managing important contextual ecological feedbacks (Morrison 2007, Termeer et al. 2011, Bergsten et al. 2014).

Local and county actors also closed integrative gaps at a greater rate than national-level actors while working on comparatively few issues. Considered holistically with the finding discussed in the previous paragraph, this result suggests that management actions that are limited in scope (i.e., bottom-up) can play an important role in adaptation to climate change and may in fact lead to enhanced institutional fitness, adaptive capacity, and the mitigation of environmental risk (Ostrom 2005, Guerrero et al. 2015, Carlisle and Gruby 2019).

\section{CONCLUSION}

In this paper, we aimed to understand when and why actors bridge integrative gaps, which are inefficiencies that occur in the absence of joint management of interdependent environmental issues. To this end, we performed analyses on a climate change adaptation network and uncovered several key attributes of actors and issues that are associated with improved social-ecological fitness, likely leading to improved environmental outcomes. We argue that at their core, integrative gaps indicate poor management practices that lead to fragmented governance systems, and that the closure of integrative gaps promotes positive environmental outcomes. Our results show that actors are more likely to close integrative gaps when pairs of issues are strongly interdependent, receive high levels of public attention, and have had more progress made on them, and that this likelihood is especially high for regional-scale, specialized, non-industry actors. Policy makers, practitioners, and stakeholders alike should prioritize management initiatives that operate under these conditions associated with closing integrative gaps. In cases where actors have less freedom to choose issues to manage, collaboration can be used as an alternative strategy to address issue interdependencies, where management is integrated through cooperation of actors from different sectors (Bodin and Nohrstedt 2016, Tosun and Lang 2017, Widmer et al. 2019). Actors may have greater freedom to choose their partners than to choose the issues they manage. Also, integrative misfit can be 
identified in order to pinpoint areas where management capacity could be strengthened to improve joint consideration for social and ecological concerns (Sayles and Baggio 2017). The practical contribution of this paper is to discover conditions that improve institutional fitness, adding to the ongoing discussion of how to improve environmental conditions in complex governance systems. Our findings suggest that to achieve more effective environmental governance, individual practitioners should reflect on whether their management activities account for environmental interdependencies.

Our findings provide empirical evidence supporting the theorized relationship between strong social-ecological fitness and positive environmental outcomes. In documenting the relationship between integrative gap closure and high levels of issue progress, our results bolster the argument that integrative gap closure leads to positive environmental outcomes. Separately, our study complements prior work that uses mental models of experts as a source of information on patterns of connectivity within environmental networks (Özesmi and Özesmi 2003, Hedlund et al. 2021). In our case, experts described the broad range of biophysical, ecological, or social processes by which many distinct environmental issues affect one another.

There are some limitations from our data collection approach that should be acknowledged. The first limitation arises from the webbased actor identification process because it inherently omits actors that lack websites, likely underestimating the number of small-scale actors in the network. Future research could utilize annual reports found on actor webpages as evidence of an actor's financial capital, because financial resources could impact integrative gap closure likelihood. A second limitation arises because we assumed that the issue interdependency network applies uniformly across the state. We likely overemphasized the importance of certain issue interdependencies in some regions. For instance, the interdependency between "nutrients" and "water quality" is especially important in northwestern Ohio, which is dominated by agriculture, and less relevant to southeastern Ohio, which is mostly forested. To this end, a direction for future research could be to systematically map issues to specific locations, then use this map as a backdrop from which to measure location-based social-ecological fitness.

Although it is important for researchers to continue to identify leverage points for improving institutional fitness, understanding when integrative gaps are closed is just a first step toward improving environmental management and governance across multiple contexts. Future research efforts would benefit from working closely with communities to develop research questions and goals that both advance theory and have practical use for practitioners, especially in the context of a rapidly changing climate (Bergsten and Zetterberg 2013, Baker et al. 2020, Jasny et al. 2021). Similarly, future research should address the qualitative aspects of gap closure and social-ecological fit. Although it is certainly worthwhile to use network analyses to draw inferences about social-ecological alignment, it is critical to understand the perspectives of practitioners as they make decisions that are more or less "fit."
Responses to this article can be read online at: https://www.ecologyandsociety.org/issues/responses. php/12996

\section{Acknowledgments:}

First and foremost, we would like to thank each of the experts who were interviewed for this project, as they contributed massively to our data set. Additionally, we thank the reviewers for this manuscript who thoughtfully offered constructive comments that have made the manuscript more well rounded. Finally, we thank Rachel Rutan, an undergraduate student in the School of Environmental and Natural Resources at Ohio State University, for her data collection work.

\section{Data Availability:}

The data and code that support the findings of this study are openly available in figshare at https://doi.org/10.6084/m9.figshare. c.5294758.v1. Ethical approval for this research study was granted by Ohio State Institutional Review Board approval number 2019 E1073.

\section{LITERATURE CITED}

Alonso Roldán, V., S. Villasante, and L. Outeiro. 2015. Linking marine and terrestrial ecosystem services through governance social networks analysis in Central Patagonia (Argentina). Ecosystem Services 16:390-402. https://doi.org/10.1016/j. ecoser.2015.02.010

Anderies, J. M., P. Ryan, and B. H. Walker. 2006. Loss of resilience, crisis, and institutional change: lessons from an intensive agricultural system in southeastern Australia. Ecosystems 9(6):865-878. https://doi.org/10.1007/s10021-006-0017-1

Angel, J. R., C. Swanson, B. M. Boustead, K. Conlon, K. R. Hall, J. L. Jorns, K. E. Kunkel, M. C. Lemos, B. M. Lofgren, T. Ontl, J. Posey, K. Stone, E. Takle, and D. Todey. 2018. Midwest. Chapter 21 in The fourth national climate assessment, volume II: Impacts, risks, and adaptation in the United States. U.S. Global Change Research Program, Washington, D.C., USA.

Angst, M. 2019. Networks of Swiss water governance issues. Studying fit between media attention and organizational activity. Society and Natural Resources 32(12):1416-1432. https://doi. org/10.1080/08941920.2018.1535102

Armitage, D. R., R. Plummer, F. Berkes, R. I. Arthur, A. T. Charles, I. J. Davidson-Hunt, A. P. Diduck, N. C. Doubleday, D. S. Johnson, M. Marschke, P. McConney, E. W. Pinkerton, and E. K. Wollenberg. 2009. Adaptive co-management for socialecological complexity. Frontiers in Ecology and the Environment 7(2):95-102. https://doi.org/10.1890/070089

Baker, Z., J. A. Ekstrom, K. D. Meagher, B. L. Preston, and L. Bedsworth. 2020. The social structure of climate change research and practitioner engagement: evidence from California. Global Environmental Change 63:102074. https://doi.org/10.1016/j. gloenvcha.2020.102074 
Barnes, M. L., Ö. Bodin, T. R. McClanahan, J. N. Kittinger, A. S. Hoey, O. G. Gaoue, and N. A. J. Graham. 2019. Socialecological alignment and ecological conditions in coral reefs. Nature Communications 10(1):2039. https://doi.org/10.1038/ s41467-019-09994-1

Berardo, R. 2009. Processing complexity in networks: a study of informal collaboration and its effect on organizational success. Policy Studies Journal 37(3):521-539. https://doi.org/10.1111/ j.1541-0072.2009.00326.x

Berardo, R., T. Olivier, and A. Lavers. 2015. Focusing events and changes in ecologies of policy games: evidence from the Paraná River Delta. Review of Policy Research 32(4):443-464. https:// doi.org/10.1111/ropr.12128

Bergsten, A., D. Galafassi, and Ö. Bodin. 2014. The problem of spatial fit in social-ecological systems: detecting mismatches between ecological connectivity and land management in an urban region. Ecology and Society 19(4):6. https://doi. org/10.5751/ES-06931-190406

Bergsten, A., T. S. Jiren, J. Leventon, I. Dorresteijn, J. Schultner, and J. Fischer. 2019. Identifying governance gaps among interlinked sustainability challenges. Environmental Science and Policy 91:27-38. https://doi.org/10.1016/j.envsci.2018.10.007

Bergsten, A., and A. Zetterberg. 2013. To model the landscape as a network: a practitioner's perspective. Landscape and Urban Planning 119:35-43. https://doi.org/10.1016/j.landurbplan.2013.06.009

Bodin, Ö. 2017. Collaborative environmental governance: achieving collective action in social-ecological systems. Science 357(6352):eaan1114. https://doi.org/10.1126/science.aan1114

Bodin, Ö., S. M. Alexander, J. Baggio, M. L. Barnes, R. Berardo, G. S. Cumming, L. E. Dee, A. P. Fischer, M. Fischer, M. Mancilla Garcia, A. M. Guerrero, J. Hileman, K. Ingold, P. Matous, T. H. Morrison, D. Nohrstedt, J. Pittman, G. Robins, and J. S. Sayles. 2019. Improving network approaches to the study of complex social-ecological interdependencies. Nature Sustainability 2 (7):551-559. https://doi.org/10.1038/s41893-019-0308-0

Bodin, Ö., B. Crona, M. Thyresson, A.-L. Golz, and M. Tengö. 2014. Conservation success as a function of good alignment of social and ecological structures and processes. Conservation Biology 28(5):1371-1379. https://doi.org/10.1111/cobi.12306

Bodin, Ö., and D. Nohrstedt. 2016. Formation and performance of collaborative disaster management networks: evidence from a Swedish wildfire response. Global Environmental Change 41:183-194. https://doi.org/10.1016/j.gloenvcha.2016.10.004

Bodin, Ö., G. Robins, R. R. J. McAllister, A. M. Guerrero, B. Crona, M. Tengö, and M. Lubell. 2016. Theorizing benefits and constraints in collaborative environmental governance: a transdisciplinary social-ecological network approach for empirical investigations. Ecology and Society 21(1): 40. https:// doi.org/10.5751/ES-08368-210140

Bodin, Ö., and M. Tengö. 2012. Disentangling intangible socialecological systems. Global Environmental Change 22(2):430-439.

https://doi.org/10.1016/j.gloenvcha.2012.01.005
Borowski, I., J.-P. Le Bourhis, C. Pahl-Wostl, and B. Barraqué. 2008. Spatial misfit in participatory river basin management: effects on social learning, a comparative analysis of German and French case studies. Ecology and Society 13(1): 7. https://doi. org/10.5751/ES-02341-130107

Brandenberger, L., K. Ingold, M. Fischer, I. Schläpfer, and P. Leifeld. 2021. Boundary spanning through engagement of policy actors in multiple issues. Policy Studies Journal: in press. https:// doi.org/10.1111/psj.12404

Buttel, F. H., and W. L. Flinn. 1977. The interdependence of rural and urban environmental problems in advanced capitalist societies: models of linkage. Sociologia Ruralis 17(2):255-281. https://doi.org/10.1111/j.1467-9523.1977.tb00870.x

Carlisle, K., and R. L. Gruby. 2019. Polycentric systems of governance: a theoretical model for the commons. Policy Studies Journal 47(4):927-952. https://doi.org/10.1111/psj.12212

Cash, D. W., W. N. Adger, F. Berkes, P. Garden, L. Lebel, P. Olsson, L. Pritchard, and O. Young. 2006. Scale and cross-scale dynamics: governance and information in a multilevel world. Ecology and Society 11(2): 8. https://doi.org/10.5751/ES-01759-110208

Cejudo, G., and C. Michel. 2017. Addressing fragmented government action: coordination, coherence, and integration. Policy Sciences 50(4):745-767. https://doi.org/10.1007/s11077-017-9281-5

Centeno, M. A., M. Nag, T. S. Patterson, A. Shaver, and A. J. Windawi. 2015. The emergence of global systemic risk. Annual Review of Sociology 41(1):65-85. https://doi.org/10.1146/ annurev-soc-073014-112317

Chen, Z., P. Huang, and Z. Zhang. 2019. Interaction between carbon dioxide emissions and eutrophication in a drinking water reservoir: a three-dimensional ecological modeling approach. Science of the Total Environment 663:369-379. https://doi. org/10.1016/j.scitotenv.2019.01.336

Cinner, J. E., and M. L. Barnes. 2019. Social dimensions of resilience in social-ecological systems. One Earth 1(1):51-56. https://doi.org/10.1016/j.oneear.2019.08.003

Cumming, G. S., D. H. M. Cumming, and C. L. Redman. 2006. Scale mismatches in social-ecological systems: causes, consequences, and solutions. Ecology and Society 11(1): 14. https://doi.org/10.5751/ES-01569-110114

Dakos, V., A. Quinlan, J. Baggio, E. Bennett, S. Burnsilver, and Ö. Bodin. 2015. Principle 2: manage connectivity. Chapter 4. Pages 80-104 in R. Biggs, M. Schlüter, and M. L. Schoon, editors. Principles for Enhancing the Resilience of Ecosystem Services. Cambridge University Press, Cambridge, UK. https://doi.org/ https://doi.org/10.1017/CBO9781316014240.005

Dennis, E. M., and E. Brondizio. 2020. Problem framing influences linkages among networks of collective action situations for water provision, wastewater, and water conservation in a metropolitan region. International Journal of the Commons 14(1): 313. https://doi.org/10.5334/ijc. 974

Dray, A., P. Perez, C. Le Page, P. D’Aquino, and I. White. 2007. Who wants to terminate the game? The role of vested interests 
and metaplayers in the ATOLLGAME experience. Simulation and Gaming 38(4):494-511. https://doi.org/10.1177/1046878107300673

Ekstrom, J. A., and B. I. Crona. 2017. Institutional misfit and environmental change: a systems approach to address ocean acidification. Science of the Total Environment 576:599-608. https://doi.org/10.1016/j.scitotenv.2016.10.114

Ekstrom, J. A., and O. R. Young. 2009. Evaluating functional fit between a set of institutions and an ecosystem. Ecology and Society 14(2): 16. https://doi.org/10.5751/ES-02930-140216

Elder, M., M. Bengtsson, and L. Akenji. 2016. An optimistic analysis of the means of implementation for sustainable development goals: thinking about goals as means. Sustainability 8(9): 962. https://doi.org/10.3390/su8090962

Emerson, K., T. Nabatchi, and S. Balogh. 2012. An integrative framework for collaborative governance. Journal of Public Administration Research and Theory 22(1):1-29. https://doi. org/10.1093/jopart/mur011

Epstein, G., J. Pittman, S. M. Alexander, S. Berdej, T. Dyck, U. Kreitmair, K. J. Rathwell, S. Villamayor-Tomas, J. Vogt, and D. Armitage. 2015. Institutional fit and the sustainability of socialecological systems. Current Opinion in Environmental Sustainability 14:34-40. https://doi.org/10.1016/j.cosust.2015.03.005

Folke, C., T. Hahn, P. Olsson, and J. Norberg. 2005. Adaptive governance of social-ecological systems. Annual Review of Environment and Resources 30(1):441-473. https://doi. org/10.1146/annurev.energy.30.050504.144511

Folke, C., L. Pritchard, Jr., F. Berkes, J. Colding, and U. Svedin. 2007. The problem of fit between ecosystems and institutions: ten years later. Ecology and Society 12(1): 30. https://doi.org/10.5751/ ES-02064-120130

Galaz, V., P. Olsson, T. Hahn, C. Folke, and U. Svedin. 2008. The problem of fit among biophysical systems, environmental and resource regimes, and broader governance systems: insights and emerging challenges. Pages 147-186 in O. R. Young, L. A. King, and $\mathrm{H}$. Schroeder, editors. Institutions and environmental change. The MIT Press, Cambridge, Massachusetts, USA. https://doi. org/10.7551/mitpress/9780262240574.003.0005

Griggs, D., M. Smith Stafford, J. Rockström, M. Öhman, O. Gaffney, G. Glaser, N. Kanie, I. Noble, W. Steffen, and P. Shyamsundar. 2014. An integrated framework for sustainable development goals. Ecology and Society 19(4): 49. https://doi. org/10.5751/ES-07082-190449

Gritsenko, D. 2018. Explaining choices in energy infrastructure development as a network of adjacent action situations: the case of LNG in the Baltic Sea region. Energy Policy 112:74-83. https:// doi.org/10.1016/j.enpol.2017.10.014

Guerrero, A. M., Ö. Bodin, R. McAllister, and K. Wilson. 2015. Achieving social-ecological fit through bottom-up collaborative governance: an empirical investigation. Ecology and Society 20 (4): 41. https://doi.org/10.5751/ES-08035-200441

Hamilton, M., A. P. Fischer, and A. Ager. 2019. A socialecological network approach for understanding wildfire risk governance. Global Environmental Change 54:113-123. https:// doi.org/10.1016/j.gloenvcha.2018.11.007
Hamilton, M., M. Lubell, and E. Namaganda. 2018. Cross-level linkages in an ecology of climate change adaptation policy games. Ecology and Society 23(2): 36. https://doi.org/10.5751/ ES-10179-230236

Hedlund, J., Ö. Bodin, and D. Nohrstedt. 2021. Policy issue interdependency and the formation of collaborative networks. People and Nature 3:236-250. https://doi.org/10.1002/pan3.10170

Henry, A. D. 2011. Ideology, power, and the structure of policy networks. Policy Studies Journal 39(3):361-383. https://doi. org/10.1111/j.1541-0072.2011.00413.x

Hileman, J., and M. Lubell. 2018. The network structure of multilevel water resources governance in Central America. Ecology and Society 23(2): 48. https://doi.org/10.5751/ ES-10282-230248

Hunter, D. R., M. S. Handcock, C. T. Butts, S. M. Goodreau, and M. Morris. 2008. ergm: a package to fit, simulate and diagnose exponential-family models for networks. Journal of Statistical Software 24(3):1-29. https://doi.org/10.18637/jss.v024.i03

Imperial, M. T., E. Johnston, M. Pruett-Jones, K. Leong, and J. Thomsen. 2016. Sustaining the useful life of network governance: life cycles and developmental challenges. Frontiers in Ecology and the Environment 14(3):135-144. https://doi.org/10.1002/fee.1249

Ingold, K., A. Moser, F. Metz, L. Herzog, H.-P. Bader, R. Scheidegger, and C. Stamm. 2018. Misfit between physical affectedness and regulatory embeddedness: the case of drinking water supply along the Rhine River. Global Environmental Change 48:136-150. https://doi.org/10.1016/j.gloenvcha.2017.11.006

Janssen, M. A., Ö. Bodin, J. M. Anderies, T. Elmqvist, H. Ernstson, R. R. J. McAllister, P. Olsson, and P. Ryan. 2006. Toward a network perspective of the study of resilience in socialecological systems. Ecology and Society 11(1): 15. https://doi. org/10.5751/ES-01462-110115

Jasny, L., J. Sayles, M. Hamilton, L. Roldan Gomez, D. Jacobs, C. Prell, P. Matous, E. Schiffer, A. M. Guererro, and M. L. Barnes. 2021. Participant engagement in environmentally focused social network research. Social Networks 66:125-138. https://doi. org/10.1016/j.socnet.2021.01.005

Jones, N. A., H. Ross, T. Lynam, P. Perez, and A. Leitch. 2011. Mental models: an interdisciplinary synthesis of theory and methods. Ecology and Society 16(1): 46. https://doi.org/10.5751/ ES-03802-160146

Kingdon, J. 1984. Agendas, alternatives, and public policies. Little, Brown, Boston, Massachusetts, USA.

Kininmonth, S., A. Bergsten, and Ö. Bodin. 2015. Closing the collaborative gap: aligning social and ecological connectivity for better management of interconnected wetlands. AMBIO 44 (1):138-148. https://doi.org/10.1007/s13280-014-0605-9

Kissinger, M., W. E. Rees, and V. Timmer. 2011. Interregional sustainability: governance and policy in an ecologically interdependent world. Environmental Science and Policy 14 (8):965-976. https://doi.org/10.1016/j.envsci.2011.05.007

Kluger, L. C., P. Gorris, S. Kochalski, M. S. Mueller, and G. Romagnoni. 2020. Studying human-nature relationships through 
a network lens: a systematic review. People and Nature 2 (4):1100-1116. https://doi.org/10.1002/pan3.10136

Lal, R., and B. A. Stewart, editors. 1994. Soil processes and water quality. Lewis Publishers, Boca Raton, Florida, USA. https://doi. org/10.1201/9781003070184-1

Le Blanc, D. 2015. Towards integration at last? The sustainable development goals as a network of targets. Sustainable Development 23(3):176-187. https://doi.org/10.1002/sd.1582

Lebel, L., E. Nikitina, C. Pahl-Wostl, and C. Knieper. 2013. Institutional fit and river basin governance: a new approach using multiple composite measures. Ecology and Society 18(1): 1. https://doi.org/10.5751/ES-05097-180101

Leifeld, P., and V. Schneider. 2012. Information exchange in policy networks. American Journal of Political Science 56(3):731-744. https://doi.org/10.1111/j.1540-5907.2011.00580.x

Leslie, H. M., and K. L. McLeod. 2007. Confronting the challenges of implementing marine ecosystem-based management. Frontiers in Ecology and the Environment 5(10):540-548. https:// doi.org/10.1890/060093

Levin, P. S., M. J. Fogarty, S. A. Murawski, and D. Fluharty. 2009. Integrated ecosystem assessments: developing the scientific basis for ecosystem-based management of the ocean. PLoS Biology 7 (1):e1000014. https://doi.org/10.1371/journal.pbio.1000014

Levin, S. 1999. A fragile dominion: complexity and the commons. Perseus, Cambridge, UK.

Locke, J. 1965. Two treaties of civil government. New American Library, New York, New York, USA.

Lubell, M. 2013. Governing institutional complexity: the ecology of games framework: the ecology of games framework. Policy Studies Journal 41(3):537-559. https://doi.org/10.1111/psj.12028

Lubell, M., L. Jasny, and A. Hastings. 2017a. Network governance for invasive species management. Conservation Letters 10:699-707. https://doi.org/10.1111/conl.12311

Lubell, M., J. M. Mewhirter, R. Berardo, and J. T. Scholz. 2017 b. Transaction costs and the perceived effectiveness of complex institutional systems. Public Administration Review 77 (5):668-680. https://doi.org/10.1111/puar.12622

Lubell, M., G. Robins, and Peng Wang. 2014. Network structure and institutional complexity in an ecology of water management games. Ecology and Society 19(4): 23. https://doi.org/10.5751/ ES-06880-190423

Lusher, D., J. Koskinen, and G. Robins. 2013. Exponential random graph models for social networks: theory, methods, and applications. Cambridge University Press, Cambridge UK. https://doi.org/10.1017/CBO9780511894701

McCann, L. 2013. Transaction costs and environmental policy design. Ecological Economics 88:253-262. https://doi.org/10.1016/ j.ecolecon.2012.12.012

McGinnis, M. D. 2011. Networks of adjacent action situations in polycentric governance. Policy Studies Journal 39(1):51-78. https://doi.org/10.1111/j.1541-0072.2010.00396.x
Metz, F., M. Angst, and M. Fischer. 2020. Policy integration: do laws or actors integrate issues relevant to flood risk management in Switzerland? Global Environmental Change 61: 101945. https://doi.org/10.1016/j.gloenvcha.2019.101945

Mewhirter, J., M. Lubell, and R. Berardo. 2018. Institutional externalities and actor performance in polycentric governance systems. Environmental Policy and Governance 28(4):295-307. https://doi.org/10.1002/eet.1816

Morrison, T. H. 2007. Multiscalar governance and regional environmental management in Australia. Space and Polity 11 (3):227-241. https://doi.org/10.1080/13562570701811551

Munsch, S. H., C. M. Greene, R. C. Johnson, W. H. Satterthwaite, H. Imaki, P. L. Brandes, and M. R. O'Farrell. 2020. Science for integrative management of a diadromous fish stock: interdependencies of fisheries, flow, and habitat restoration. Canadian Journal of Fisheries and Aquatic Sciences 77 (9):1487-1504. https://doi.org/10.1139/cjfas-2020-0075

O'Brien, K., B. Hayward, and F. Berkes. 2009. Rethinking social contracts: building resilience in a changing climate. Ecology and Society 14(2): 12. https://doi.org/10.5751/ES-03027-140212

Olsson, P., C. Folke, V. Galaz, T. Hahn, and L. Schultz. 2007. Enhancing the fit through adaptive co-management: creating and maintaining bridging functions for matching scales in the Kristianstads Vattenrike Biosphere Reserve, Sweden. Ecology and Society 12(1): 28. https://doi.org/10.5751/ES-01976-120128

Ostrom, E. 2005. Understanding institutional diversity. Princeton University Press, Princeton, New Jersey, USA.

Özesmi, U., and S. Özesmi. 2003. A participatory approach to ecosystem conservation: fuzzy cognitive maps and stakeholder group analysis in Uluabat Lake, Turkey. Environmental Management 31(4):518-531. https://doi.org/10.1007/s00267-002-2841-1

Pham-Truffert, M., F. Metz, M. Fischer, H. Rueff, and P. Messerli. 2020. Interactions among sustainable development goals: knowledge for identifying multipliers and virtuous cycles. Sustainable Development 28(5):1236-1250. https://doi.org/10.1002/ $\underline{\mathrm{sd} .2073}$

Pittman, J., and D. Armitage. 2017. How does network governance affect social-ecological fit across the land--sea interface? An empirical assessment from the Lesser Antilles. Ecology and Society 22(4): 5. https://doi.org/10.5751/ ES-09593-220405

Qiu, J., C. B. Wardropper, A. R. Rissman, and M. G. Turner. 2017. Spatial fit between water quality policies and hydrologic ecosystem services in an urbanizing agricultural landscape. Landscape Ecology 32(1):59-75. https://doi.org/10.1007/s10980-016-0428-0

R Core Team. 2020. R: a language and environment for statistical computing. R Foundation for Statistical Computing, Vienna, Austria.

Reyers, B., and E. R. Selig. 2020. Global targets that reveal the social-ecological interdependencies of sustainable development. Nature Ecology and Evolution 4(8):1011-1019. https://doi. org/10.1038/s41559-020-1230-6 
Rittel, H. W. J., and M. M. Webber. 1973. Dilemmas in a general theory of planning. Policy Sciences 4(2):155. https://doi. org/10.1007/BF01405730

Robins, G., L. Bates, and P. Pattison. 2011. Network governance and environmental management: conflict and cooperation. Public Administration 89(4):1293-1313. https://doi.org/10.1111/ j.1467-9299.2010.01884.X

Robins, G., P. Pattison, Y. Kalish, and D. Lusher. 2007. An introduction to exponential random graph $\left(\mathrm{p}^{*}\right)$ models for social networks. Social Networks 29(2):173-191. https://doi.org/10.1016/ j.socnet.2006.08.002

Roesch-McNally, G., M. Chang, M. Dalton, S. Lowe, C. Luce, C. May, G. Morishima, P. Mote, A. Petersen, E. And, Y. American, Trust, and D. Washington. 2020. Beyond climate impacts: knowledge gaps and process-based reflection on preparing a regional chapter for the Fourth National Climate Assessment. Weather, Climate, and Society 12: 337-350. https:// doi.org/10.1175/WCAS-D-19-0060.1

Rousseau, J.-J. 1973. The social contract and discourses. Everyman, London, UK.

Sayles, J. S., and J. A. Baggio. 2017. Social-ecological network analysis of scale mismatches in estuary watershed restoration. Proceedings of the National Academy of Sciences of the United States of America 114(10): E1776-E1785. https://doi.org/10.1073/ pnas. 1604405114

Sayles, J. S., M. Mancilla Garcia, M. Hamilton, S. M. Alexander, J. A. Baggio, A. P. Fischer, K. Ingold, G. R. Meredith, and J. Pittman. 2019. Social-ecological network analysis for sustainability sciences: a systematic review and innovative research agenda for the future. Environmental Research Letters 14(9): 093003. https://doi.org/10.1088/1748-9326/ab2619

Stafford-Smith, M., D. Griggs, O. Gaffney, F. Ullah, B. Reyers, N. Kanie, B. Stigson, P. Shrivastava, M. Leach, and D. O'Connell. 2017. Integration: the key to implementing the sustainable development goals. Sustainability Science 12(6):911-919. https:// doi.org/10.1007/s11625-016-0383-3

Taylor, K., T. Brummer, M. L. Taper, A. Wing, and L. J. Rew. 2012. Human-mediated long-distance dispersal: an empirical evaluation of seed dispersal by vehicles. Diversity and Distributions 18(9/10):942-951. https://doi.org/10.1111/ j.1472-4642.2012.00926.x

Termeer, C., A. Dewulf, H. van Rijswick, A. van Buuren, D. Huitema, S. Meijerink, T. Rayner, and M. Wiering. 2011. The regional governance of climate adaptation: a framework for developing legitimate, effective, and resilient governance arrangements. Climate Law 2(2):159-179. https://doi.org/10.1163/ CL-2011-032

Tosun, J., and A. Lang. 2017. Policy integration: mapping the different concepts. Policy Studies 38(6):553-570. https://doi. org/10.1080/01442872.2017.1339239

Trein, P., I. Meyer, and M. Maggetti. 2019. The integration and coordination of public policies: a systematic comparative review. Journal of Comparative Policy Analysis: Research and Practice 21(4):332-349. https://doi.org/10.1080/13876988.2018.1496667
Treml, E. A., P. I. J. Fidelman, S. Kininmonth, J. A. Ekstrom, and Ö. Bodin. 2015. Analyzing the (mis)fit between the institutional and ecological networks of the Indo-West Pacific. Global Environmental Change 31:263-271. https://doi.org/10.1016/j. gloenvcha.2015.01.012

Wang, S., S. Song, J. Zhang, X. Wu, and B. Fu. 2021. Achieving a fit between social and ecological systems in drylands for sustainability. Current Opinion in Environmental Sustainability 48:53-58. https://doi.org/10.1016/j.cosust.2020.09.008

Widmer, A., L. Herzog, A. Moser, and K. Ingold. 2019. Multilevel water quality management in the international Rhine catchment area: how to establish social-ecological fit through collaborative governance. Ecology and Society 24(3): 27. https://doi. org/10.5751/ES-11087-240327

Willis, C. G., B. R. Ruhfel, R. B. Primack, A. J. Miller-Rushing, J. B. Losos, and C. C. Davis. 2010. Favorable climate change response explains non-native species' success in Thoreau's woods. PLoS ONE 5(1): e8878. https://doi.org/10.1371/journal. pone. 0008878

Wlezien, C. 2005. On the salience of political issues: the problem with 'most important problem.' Electoral Studies 24(4):555-579. https://doi.org/10.1016/j.electstud.2005.01.009

Young, O. R. 2002. The institutional dimensions of environmental change: fit, interplay, and scale. The MIT Press, Cambridge, Massachusetts, USA. https://doi.org/10.7551/ mitpress/3807.001.0001

Zhu, J.-H. 1992. Issue competition and attention distraction: a zero-sum theory of agenda-setting. Journalism Quarterly 69 (4):825-836. https://doi.org/10.1177/107769909206900403 
Appendix 1

\section{Description and interpretation of control parameters from exponential random graph models}

We utilized the "statnet" (Handcock et al. 2018) and "ERGM" (Hunter et al. 2008) packages in $\mathrm{R}$ (R Core Team 2019) to perform all our analyses. The burn-in for our models was set to 500,000, the sample size and interval were both set to 10,000, and the seed was set to 123 .

We included two parameters in the model to control for structural characteristics of the network. First, the edges parameter shows the general tendency for actors to work on issues (i.e., the likelihood of actors to form social-ecological linkages). As such, the edges parameter essentially measures the density of the network - it represents how many social-ecological linkages are present versus how many are possible. Second, the geometrically weighted degree distribution for the actor level ( $g$ wbldegree) term measures the distribution of actors' ties to climate adaptation issues (i.e., the number of issues that each actor is linked to). Degree refers to the total number of ties attached to a node; the actor-level degree distribution measures the number of issues that are tied to each actor. The parameter for the actor-level degree distribution ( gwbldegree) term indicates the extent to which a tie decreases the likelihood of an additional tie, according to a decay parameter, $\theta_{s}$ (Hunter 2007). To optimize and ensure model convergence, we set the decay parameter $\left(\theta_{s}\right)$ to 2 .

Parameter estimates for control terms are included in all four models and are displayed in Table 3. The negative parameter estimate for edges is unsurprising, indicating that the network is sparsely connected through social-ecological linkages. The negative and significant parameter estimate for the actor-level degree distribution term (gwbldegree) indicates that it is more likely for a given issue to be managed by actors who manage many additional issues, as opposed to actors who work on only a few issues. 
Appendix 2

\section{ERGM-terms, data type, and $\mathrm{R}$ objects for each parameter from exponential random graph models}

Table A2.1 displays information pertaining to each parameter included in the exponential random graph models. Included in this table for each parameter are the specific ERGM-terms used, the type of data it employs, and the named $\mathrm{R}$ object the authors used in their script. The $\mathrm{R}$ code used in this analysis are available at https://doi.org/10.6084/m9.figshare.c.5294758.v1.

\begin{tabular}{|l|l|l|l|}
\hline Term & ERGM-Term & Data Class & R Object \\
\hline $\begin{array}{l}\text { Integrative Gap } \\
\text { Closure }\end{array}$ & "edgecov" & Covariate matrix & "ec_meanconnectivity_mat" \\
\hline $\begin{array}{l}\text { Issue Concern - Gap } \\
\text { Closure }\end{array}$ & "edgecov" & Covariate matrix & "ec_concern_mat2" \\
\hline $\begin{array}{l}\text { Issue Progress - Gap } \\
\text { Closure }\end{array}$ & "edgecov" & Covariate matrix & "ec_progress_mat2" \\
\hline $\begin{array}{l}\text { Actor Type - Gap } \\
\text { Closure }\end{array}$ & "edgecov" & Covariate matrix & "ec_actortypeX_mat" \\
\hline $\begin{array}{l}\text { Actor Type - Issue } \\
\text { Engagement }\end{array}$ & "b1factor" & $\begin{array}{l}\text { Actor-level node } \\
\text { attribute }\end{array}$ & "OrgType" \\
\hline $\begin{array}{l}\text { Actor Scope - Gap } \\
\text { Closure }\end{array}$ & "edgecov" & Covariate matrix & "ec_orgscopeX_mat" \\
\hline $\begin{array}{l}\text { Actor Scope - Issue } \\
\text { Engagement }\end{array}$ & "b1factor" & $\begin{array}{l}\text { Actor-level node } \\
\text { attribute }\end{array}$ & "Scope" \\
\hline Edges & "edges" & Network-level & N/A \\
\hline $\begin{array}{l}\text { Actor-level Degree } \\
\text { Distribution }\end{array}$ & "gwb1degree" & Network-level & N/A \\
\hline $\begin{array}{l}\text { Issue Concern - Issue } \\
\text { Engagement }\end{array}$ & "b2cov" & $\begin{array}{l}\text { Issue-level node } \\
\text { covariate }\end{array}$ & "IssueConcern" \\
\hline $\begin{array}{l}\text { Issue Progress - Issue } \\
\text { Engagement }\end{array}$ & "b2cov" & $\begin{array}{l}\text { Issue-level node } \\
\text { covariate }\end{array}$ & "IssueProgress" \\
\hline
\end{tabular}

Table A2.1: All terms included in exponential random graph models are shown with the corresponding ERGM-term used in the R package "ERGM" (Hunter et al. 2008), the type of data it requires, and its associated data object referenced in the author's models. 


\section{Appendix 3}

\section{Model diagnostics}

We measure goodness-of-fit for the parameters included in the models. The plots show good fit for the parameters that were included in the models (Figure A3.1). Additionally, we considered several parameters that were not included in the models - dyad-wise shared partners and minimum geodesic distance - which we compared to estimates from 100 simulated networks based on model specification, for each of the four models (Figure A3.2). The thick lines in each plot indicate empirical statistics and are displayed against corresponding boxplots that display the simulated distribution of the network statistic. The models slightly underestimated minimum geodesic distance in the simulated networks (Figure A3.2).

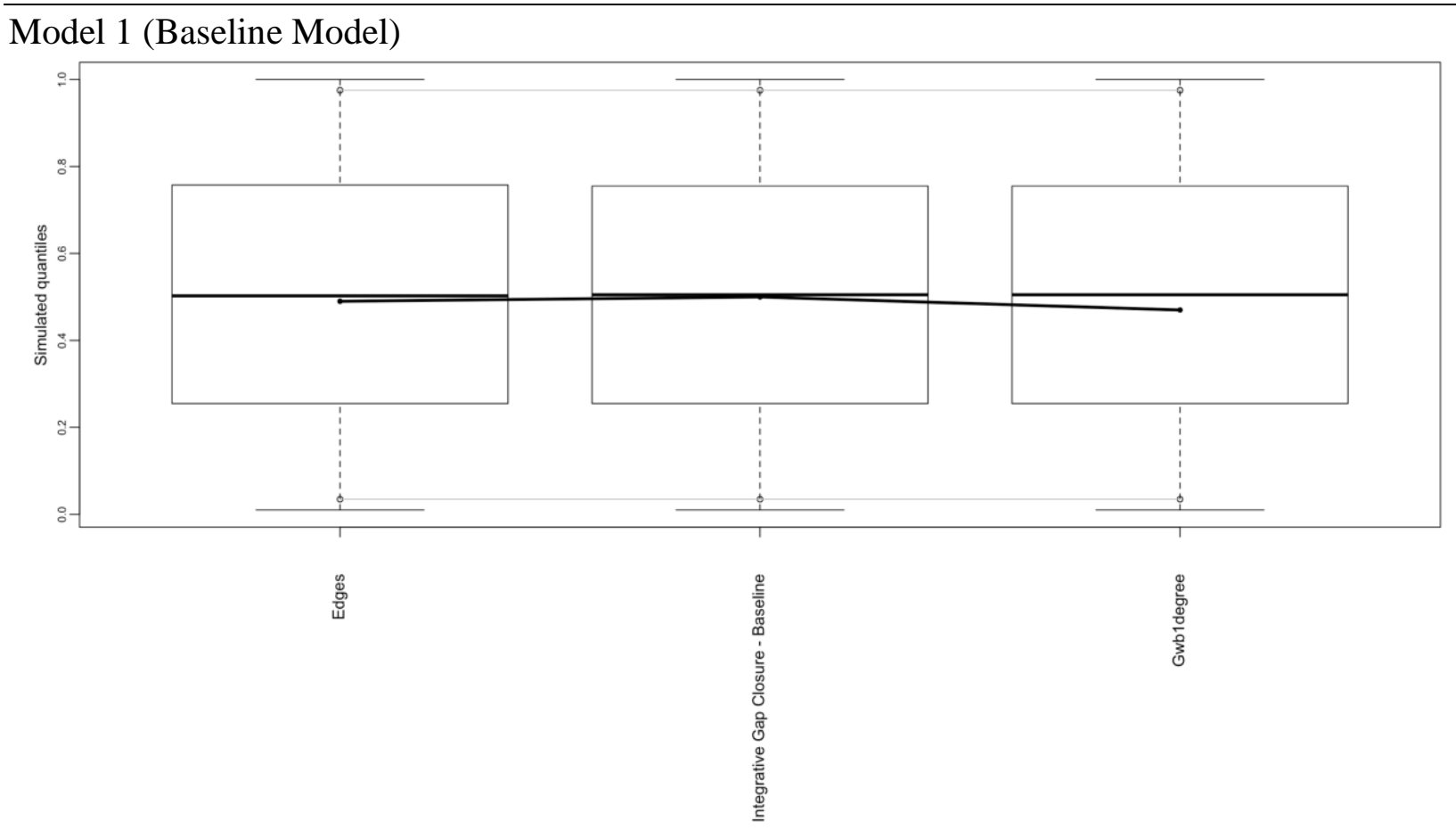

Model 2 (Integrative Gap Closure Hypotheses) 


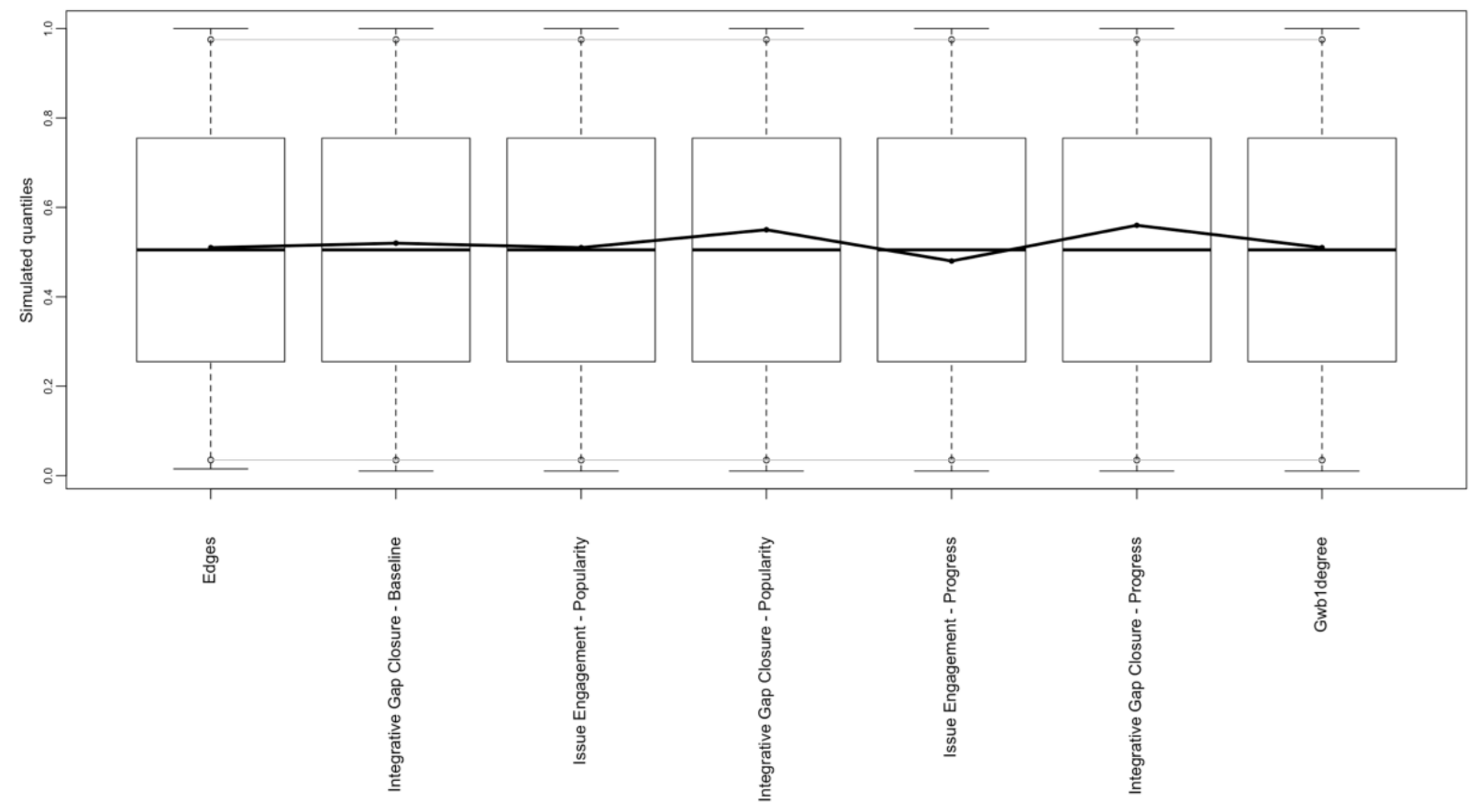

Model 3 (Actor Type Effects)

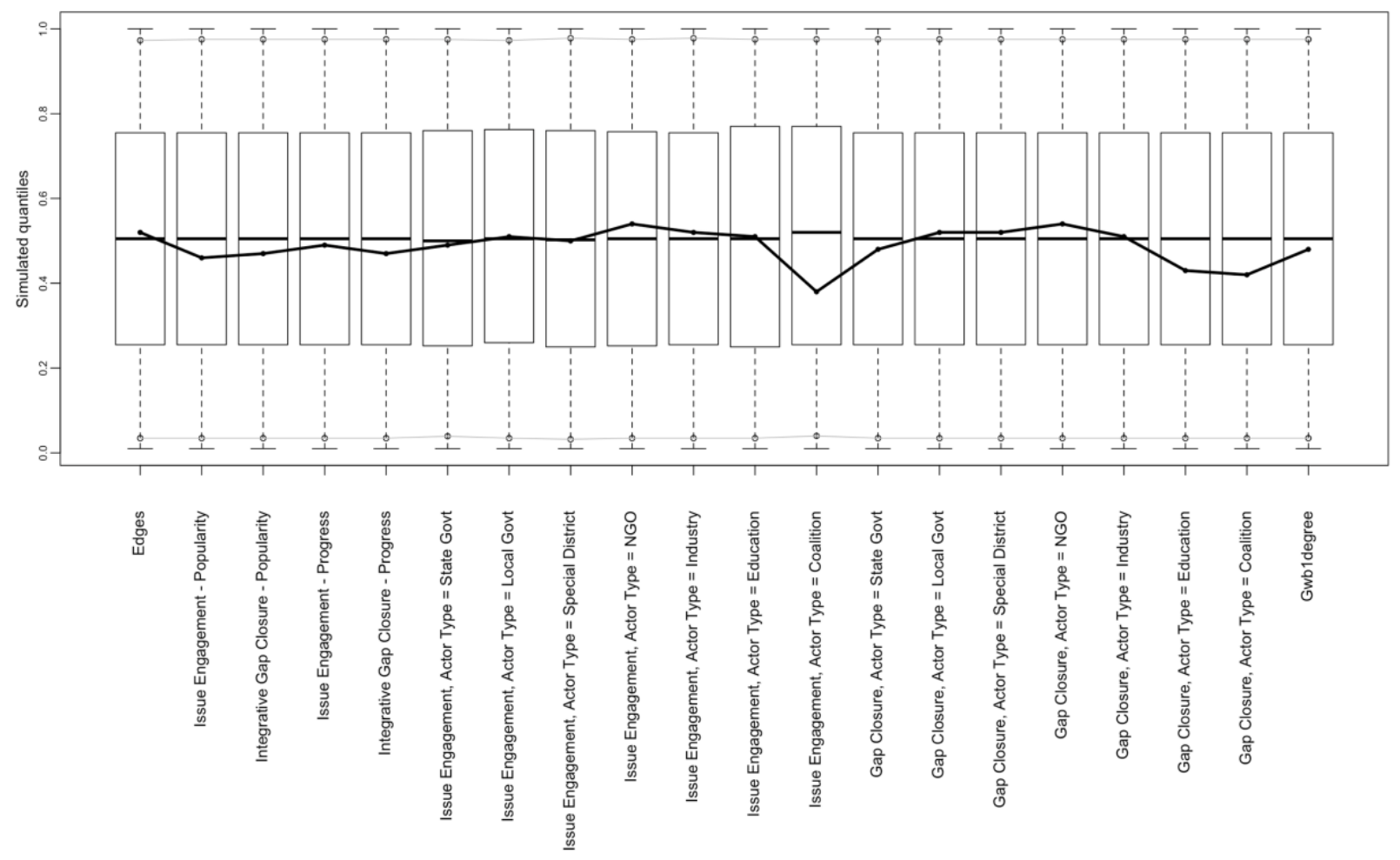




\section{Model 4 (Actor Scope Effects)}

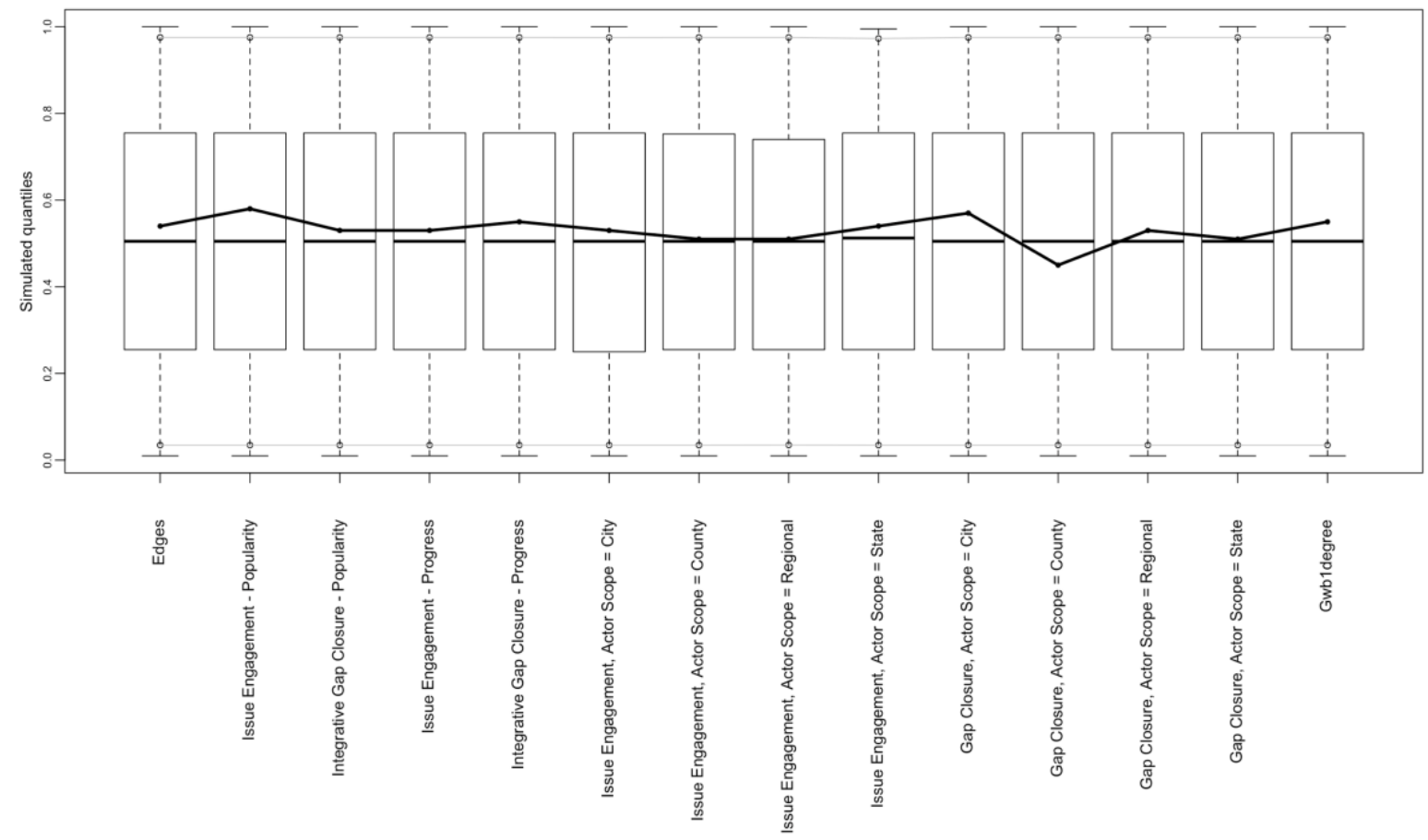

Figure A3.1: Goodness of fit for model parameters.

Model 1 (Baseline Model)
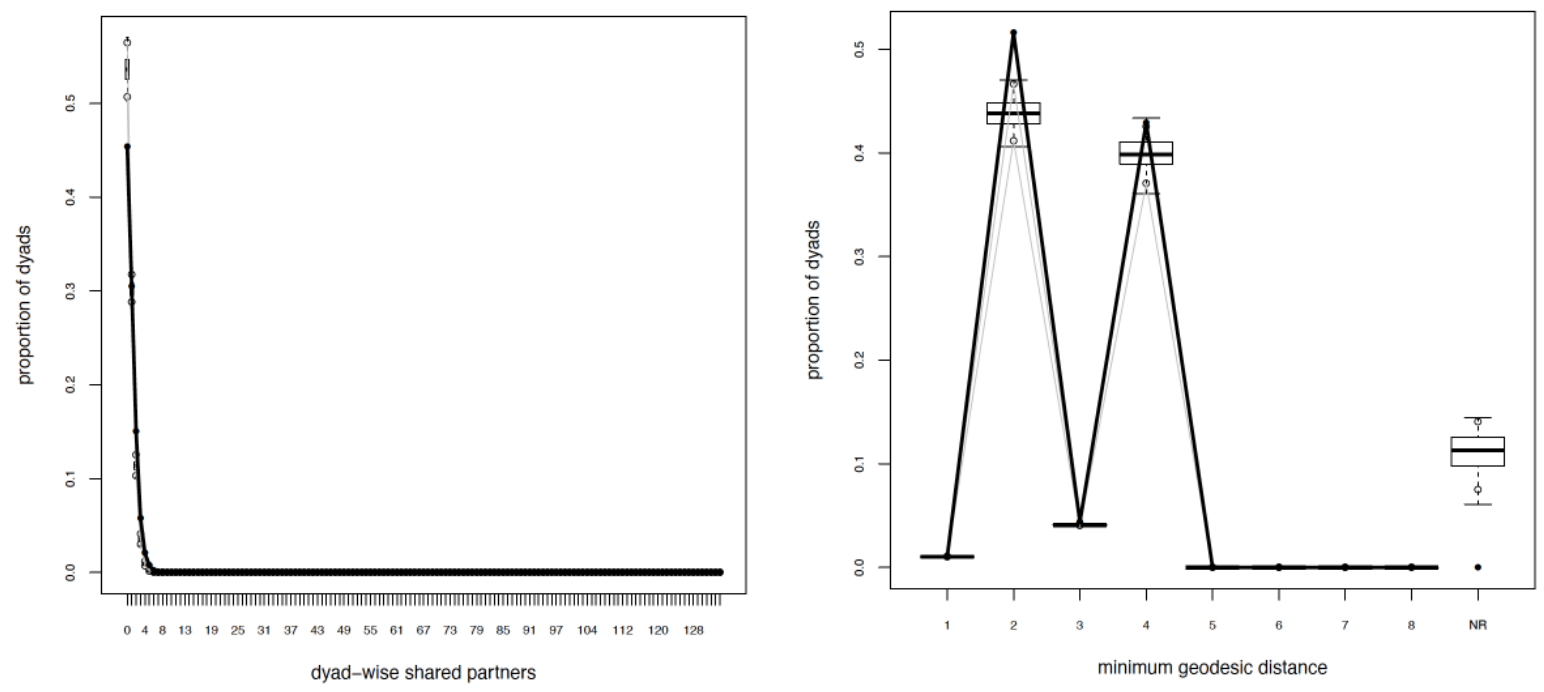

Model 2 (Integrative Gap Closure Hypotheses) 

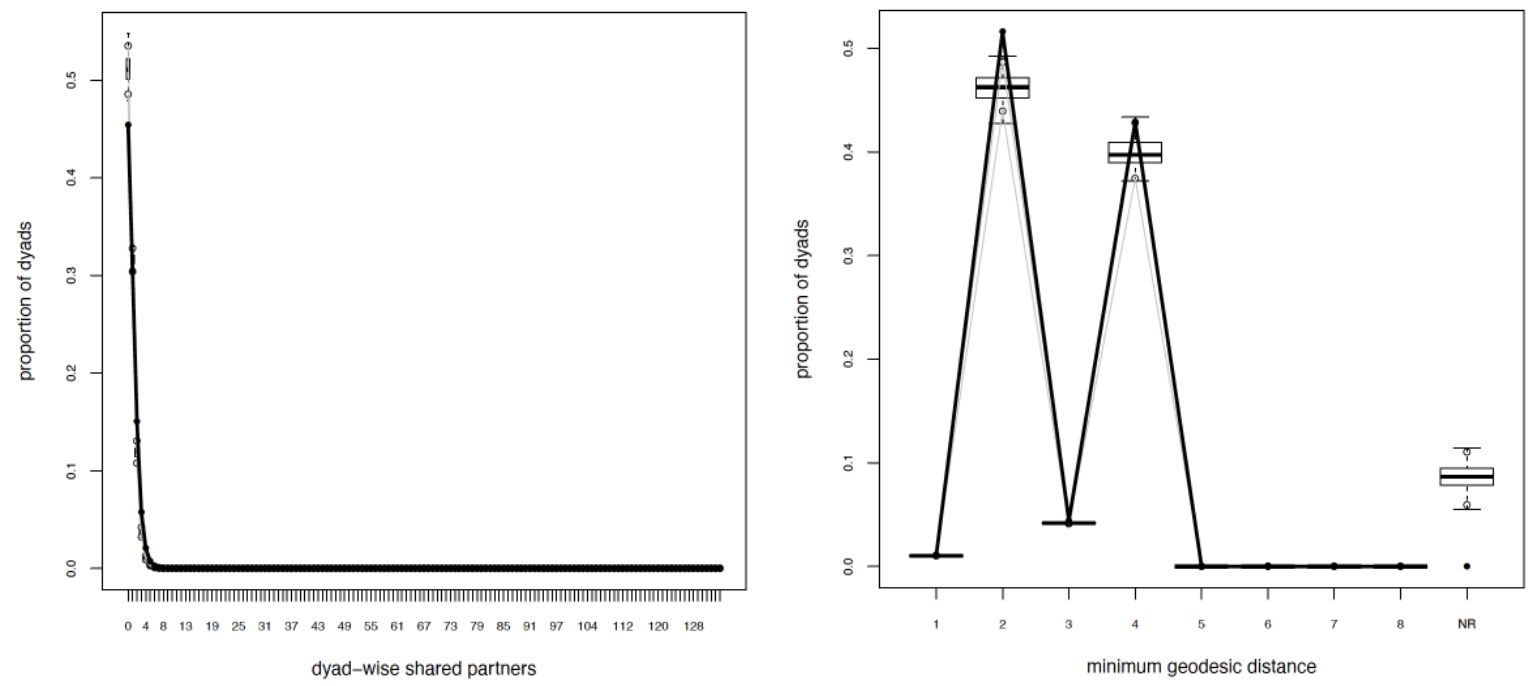

Model 3 (Actor Type Effects)
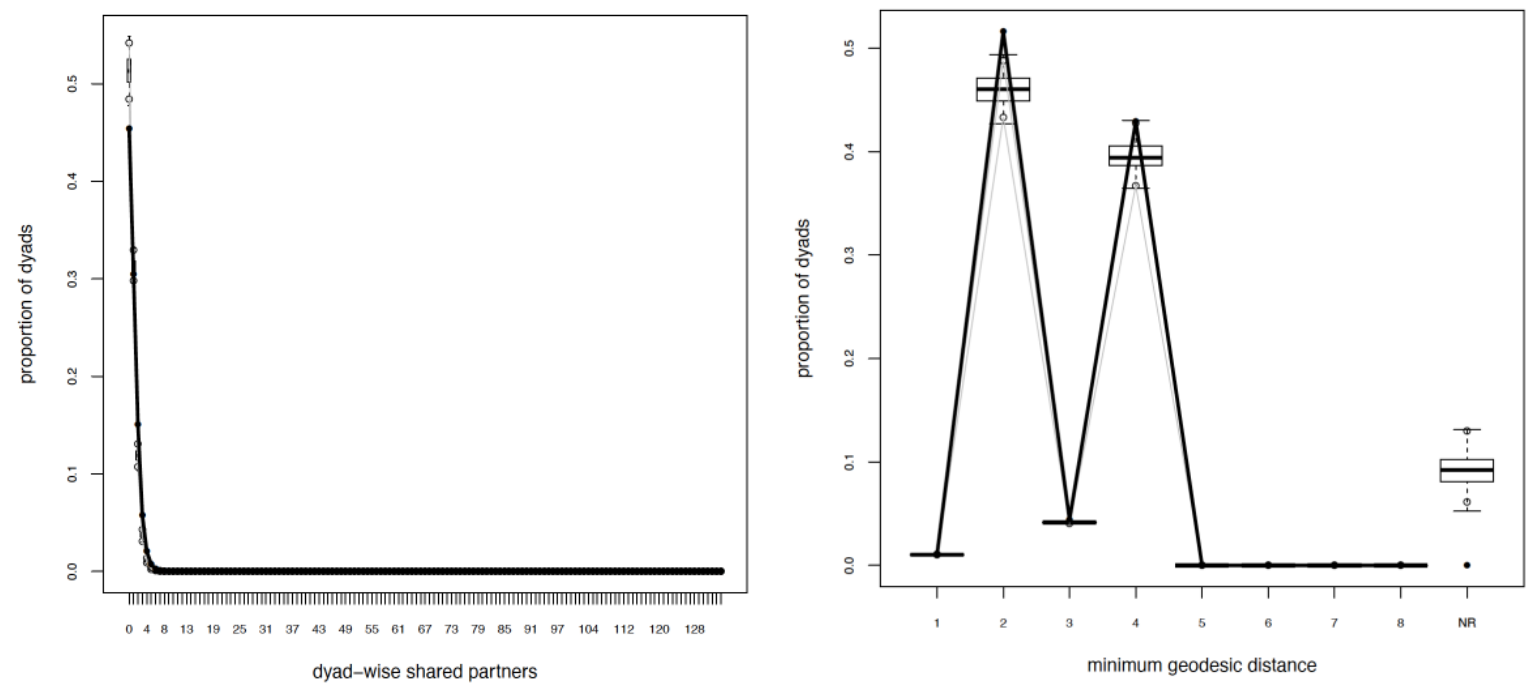

Model 4 (Actor Scope Effects) 

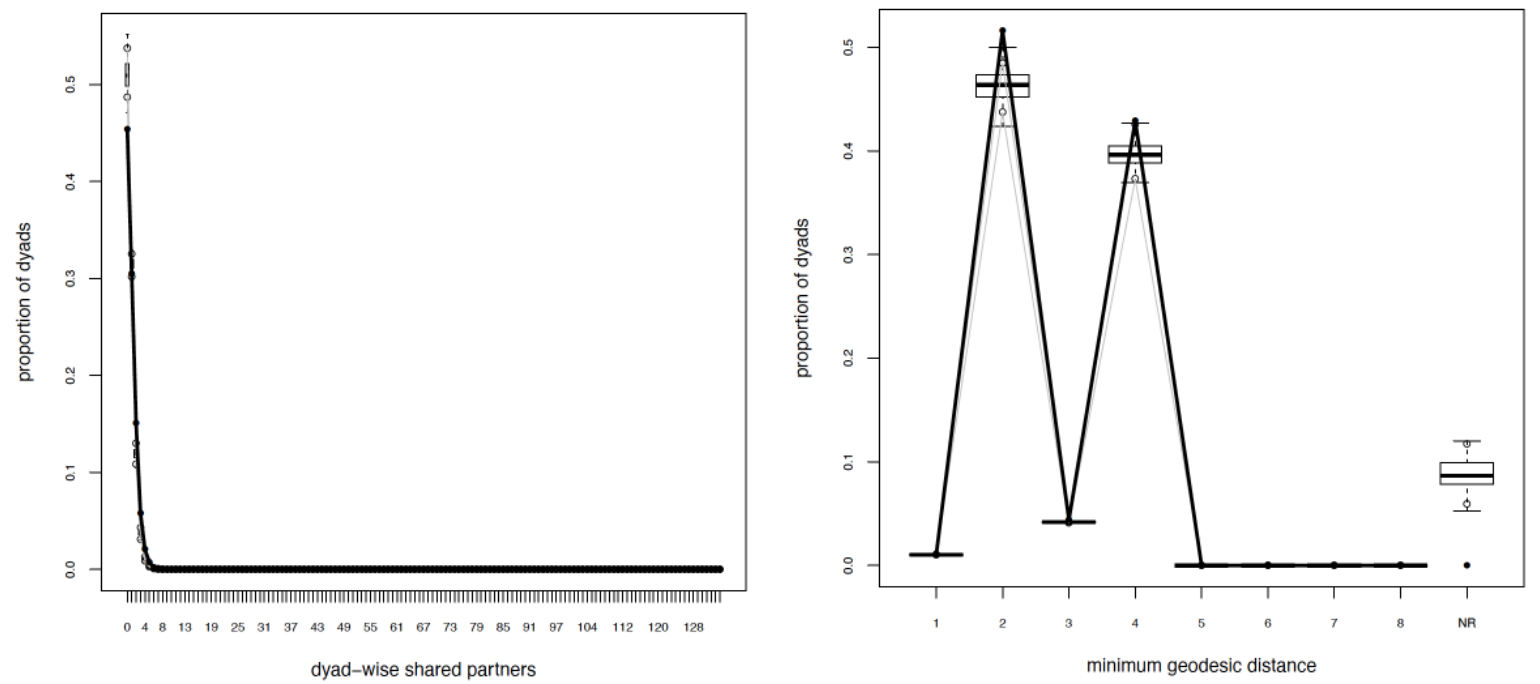

Figure A3.2: Fit for parameters not included in the models, including dyad-wise shared partners and minimum geodesic distance.

\section{LITERATURE CITED}

Handcock, M., D. Hunter, C. Butts, S. Goodreau, P. Krivitsky, and M. Morris. 2018. Ergm: Fit, Simulate and Diagnose Exponential-Family Models for Networks. The Statnet Project. URL:http://www.statnet.org.

Hunter, D. 2007. Curved Exponential Family Models for Social Networks. Social Networks, 29, 216-230. https://doi.org/10.1016/j.socnet.2006.08.005.

Hunter, D., M. Handcock, C. Butts, S. Goodreau, and M. Morris M. 2008. Ergm: A Package to Fit, Simulate and Diagnose Exponential-Family Models for Networks. Journal of Statistical Software, 24(3), 1-29.

R Core Team (2019). R: A language and environment for statistical computing. R Foundation for Statistical Computing, Vienna, Austria. URL https://www.R-project.org/ 